\title{
DISEÑO DE ALGORITMOS DE CÁLCULO DE RETARDO DE ONDAS ULTRASÓNICAS PARA LA DETERMINACIÓN DEL MÓDULO ELÁSTICO DEL HORMIGÓN REFORZADO CON FIBRA DE VIDRIO Y PROPUESTA DE DOSIFICACIÓN ÓPTIMA
}

\author{
por \\ Francisco Javier Luna Molina \\ Una tesina dirigida al Departamento de Mecánica de Estructuras e Ingeniería Hidráulica, \\ como un requisito parcial de los requerimientos para el título de
}

\section{MÁSTER DE ESTRUCTURAS}

Director: Dr. Guillermo Rus Carlborg

Departamento de Mecánica de Estructuras e Ingeniería Hidráulica

Universidad de Granada, E.T.S.I.C.C.P.

18071 Granada, España

Septiembre 2012 


\section{Resumen}

Son de sobra conocidas las mejoras que aportan las fibras de vidrio al hormigón, tanto en su comportamiento reológico como estructural. Pero todas estas ventajas se han logrado hasta ahora a costa de asumir porcentajes de FV del orden del $3 \%$ sobre el peso del hormigón y superiores, lo que dota al HRFV de un coste económico elevado y lo aleja, por tanto, del mercado.

Con el fin de poder convertir el HRFV en un material competitivo y de aprovechar su potencial, se proponen en este estudio diversas dosificaciones con cantidades de FV mucho menores de las habituales (en concreto, desde 0,4\% hasta $1,5 \%$ ) y con longitudes de fibras diferentes (12 $\mathrm{mm}$ y $36 \mathrm{~mm}$ ).

Los HRFV fabricados se estudian de forma comparativa entre sí, con el propósito de conocer la dosis óptima de FV, y respecto a un hormigón convencional sin fibras, confeccionado para ver las mejoras sobre éste.

La comparación entre las distintas dosificaciones se ha llevado a cabo fundamentalmente analizando los resultados de los módulos elásticos de las muestras de hormigón confeccionadas, y que han sido obtenidos mediante la aplicación de técnicas no destructivas, en concreto, ultrasonidos.

En este sentido, se han aportado diversos algoritmos de cálculo de retardo (o tiempo de vuelo) de ondas ultrasónicas, y se ha realizado una comparación entre todos ellos y los que existen en el mercado con el fin de hallar de la manera más exacta ciertas propiedades físicas y elásticas del hormigón que se necesitan conocer para deducir cuál de las dosificaciones es la finalmente elegida. 


\section{Agradecimientos}

En primer lugar, me gustaría dar las gracias a mi tutor, el doctor Guillermo Rus Carlborg, del Departamento de Mecánica de Estructuras e Ingeniería Hidráulica, por darme la oportunidad de estudiar un campo tan atractivo como el de los materiales avanzados y por prestarme parte de su tiempo durante estos meses.

Agradecer a mi familia el apoyo constante, su paciencia y su ánimo por intentar siempre que me mantenga con ilusión y que piense que el esfuerzo tiene siempre recompensa.

No me puedo olvidar de mis compañeros del laboratorio de Evaluación no destructiva de la Universidad de Granada, con quienes he pasado tantas horas y quienes me han dado tantos consejos y compartido sus experiencias conmigo.

Mencionar también al profesor José Rodríguez Montero por interesarse en el desarrollo de este trabajo y facilitarme su elaboración en tiempo y forma, así como por transmitirme sus conocimientos envidiables sobre el hormigón y permitir hacer uso de los equipos del Laboratorio de Ingeniería de la Construcción cuando me han sido necesarios.

Finalmente, agradecer a Salvador Mansilla Vera por contagiarme de su iniciativa y su apuesta por la investigación.

Los presentes trabajos se desarrollan en el contexto del contrato firmado por la Agrupación de Interés Económico Proyecto EPD con la Universidad de Granada, para el desarrollo del proyecto de investigación "Proyecto de Estructuras y Pavimentos Discontinuos". Parte de los datos relativos a ensayos de hormigón con fibra de vidrio ya se recogen en la Guía de Aplicación en desarrollo para los productos resultantes de dicho estudio. 
ÍNDICE

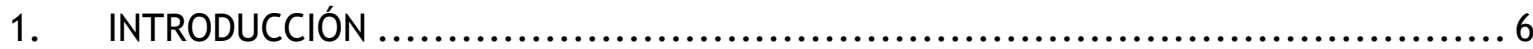

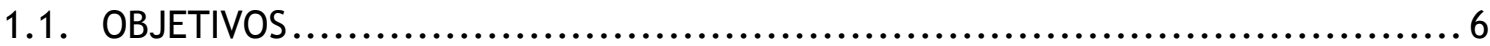

1.2. ESTADO DEL ARTE ......................................................... 6

1.2.1. TÉCNICAS DE CÁLCULO DE RETARDO EN MATERIALES NO ACÚSTICAMENTE

TRANSPARENTES (HETEROGÉNEOS Y DISPERSIVOS) .................................6

1.3. PRESENTACIÓN DEL FENÓMENO Y DE LAS VARIABLES DE ESTUDIO ............... 8

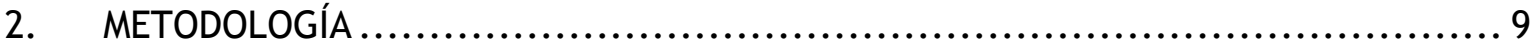

2.1. MATERIALES Y ESPECÍMENES ............................................. 9

2.2. METODOLOGÍA PARA LA DETERMINACIÓN DEL MÓDULO ELÁSTICO DADO UN

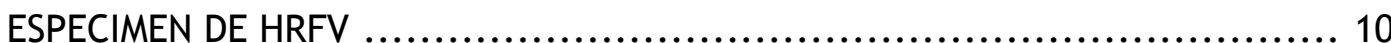

2.2.1. METODOLOGÍA...................................................... 10

2.2.2. TEORÍA DE LA SEÑAL. COMPARACIÓN DE ALGORITMOS DE CÁLCULO DE RETARDO DE ONDAS .......................................................... 11

2.2.3. ULTRASONIDOS. CÁLCULO DE MÓDULO ELÁSTICO ........................ 14

2.2.4. TEORÍA DE ERRORES ............................................... 15

2.3. VALIDACIÓN MEDIANTE TÉCNICAS DESTRUCTIVAS............................. 16

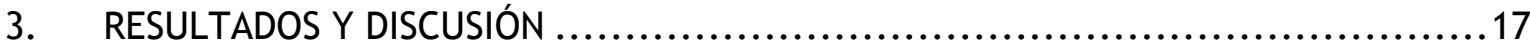

3.1. PROCESO Y ANÁLISIS DE DATOS ............................................ 17

3.1.1. INTRODUCCIÓN ...................................................... 17

3.1.2. RETARDO DE ONDAS P Y MÓDULO DE YOUNG ......................... 17

3.1.3. IDONEIDAD DEL MÉTODO ............................................ 19

3.1.4. INFLUENCIA DE LAS FIBRAS DE VIDRIO EN EL MÓDULO ELÁSTICO .......... 20

3.1.5. INFLUENCIA DEL TIEMPO DE CURADO EN EL MÓDULO ELÁSTICO ........... 22

3.1.6. INFLUENCIA DE LA FRECUENCIA DE EXCITACIÓN EN EL RETARDO DE LAS

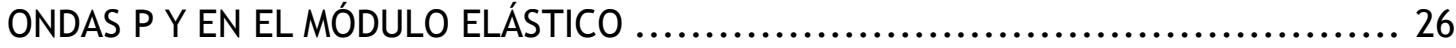

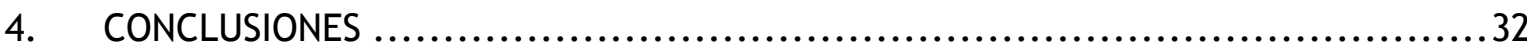

4.1. MÉTODOS DE CÁLCULO DE RETARDO......................................... 32

4.2. DOSIFICACIÓN ÓPTIMA .................................................... 32

4.3. PROPUESTAS DE MEJORA, LÍNEAS FUTURAS DE INVESTIGACIÓN Y APLICACIONES 33

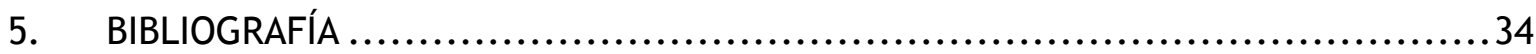




\section{INTRODUCCION}

\subsection{OBJETIVOS}

Los objetivos de este estudio son responder a ciertos interrogantes relativos al hormigón reforzado con fibra de vidrio (HRFV, en adelante).

Lo primero que se cuestiona en este estudio es la posibilidad o no de determinar el módulo elástico del HRFV, un material heterogéneo y dispersivo, mediante evaluación no destructiva (en adelante, END), y de proporcionarlo con una cierta fiabilidad, es decir, en términos de su media y de una desviación típica asumible.

Para resolver la pregunta, se han propuesto diversos algoritmos de cálculo de retardo de ondas ultrasónicas con objeto de obtener el módulo elástico con las máximas garantías de fiabilidad.

Si se consiguiera obtener de forma fiable el módulo elástico, y la respuesta a esta pregunta fuese por tanto afirmativa, se podrían, por un lado, estudiar diferentes dosificaciones de HRFV con objeto de identificar el contenido óptimo de FV, en \% en peso, que debería llevar un hormigón para que su resistencia a flexotracción fuese la mayor posible.

Por otro lado, sería fidedigno comparar, en términos de características mecánicas y económicas, el HRFV cuya dosificación resultase ser la óptima con el tradicional hormigón armado (HA, en adelante), y concluir si este avanzado material puede ser un válido sustituto del HA convencional.

\subsection{ESTADO DEL ARTE}

\subsubsection{TÉCNICAS DE CÁLCULO DE RETARDO EN MATERIALES NO ACÚSTICAMENTE TRANSPARENTES (HETEROGÉNEOS Y DISPERSIVOS)}

Se recurre en este estudio a técnicas no destructivas, es decir, que no causan daños estructurales al material en cuestión, puesto que este tipo de métodos son ampliamente utilizados para determinar las propiedades del hormigón endurecido y para evaluar la condición del mismo [4].

Los métodos de END se aplican a las construcciones de hormigón por muchas razones, como por ejemplo llevar a cabo un control de calidad de una nueva construcción o evaluar un hormigón viejo susceptible de rehabilitación, y son técnicas cuya aplicación va en aumento.

Se ha utilizado concretamente en este estudio el método de las ondas de presión. Las ondas de presión ocurren cuando se aplica de forma instantánea una presión sobre la superficie de un cuerpo, y ésta se deforma. Esta perturbación se propaga a través del sólido, al igual que una onda de sonido viaja a través del aire. La velocidad de propagación de la onda de presión en un cuerpo elástico es función de las variables elásticas del material y de la geometría del sólido. Las diferencias que se presenten entre estas variables proporcionarán determinados valores de velocidad de transmisión por el medio y permitirán pues inferir las características del cuerpo estudiado atendiendo a estas diferencias. 
Por otro lado, es ampliamente conocido que la velocidad puede hallarse conociendo el espacio recorrido y el tiempo empleado en recorrerlo (retardo, en adelante). Generalmente, el espacio es conocido, y viene dado por el espesor del espécimen a ensayar. Queda la incógnita del retardo. Determinar con precisión el retardo entre señales es un problema frecuente en multitud de aplicaciones: ultrasonidos, comunicaciones, biomedicina, caracterización de materiales, etc. puesto que, para obtener una alta fiabilidad en la END, no basta con utilizar los métodos clásicos.

En los últimos años, los potentes ordenadores han permitido la emergencia de sofisticados algoritmos dedicados al procesamiento e interpretación de una gran cantidad de información, muchos de ellos los cuales han sido propuestos concretamente para estimar el retardo de estas ondas: determinación del paso de la señal por un umbral o de la posición del máximo, métodos de Monte Carlo, estimadores basados en la correlación o "matched filtering", en la transformada de Hilbert, estimación del cambio de fase, estimación utilizando las propiedades de la transformada de Fourier, promediado de la señal, análisis de espectro de frecuencia, espectros que varían en el tiempo ("wavelet transform"), redes neuronales, análisis autorregresivo, etc.

En la década de los noventa, uno de los métodos más extendidos era el "wavelet transform", tal y como se describe en [8], donde se utiliza para mejorar la detección ultrasónica de defectos. Se aproxima al método "split spectrum processing" (SPP, en adelante) pero en este caso el ancho de banda relativo es constante, dando como resultado un banco de filtro con una estructura de ventana autoajustable que puede mostrar la variación temporal de los componentes espectrales de la señal con la variación de las resoluciones. Dicha propiedad hace este método extremadamente útil para la detección de defectos ocultos bajo ruido de fondo.

Redouane Drai es uno de los autores que más contribuciones en el campo del procesamiento de señales ha realizado. En el año 2000 [1], se proponen diversos métodos que utilizan algoritmos de procesamiento de la señal para mejorar el ratio señal-ruido, que han sido implementados en ordenador y que permiten su utilización en tiempo real para el procesado de los resultados de los test de evaluación no destructiva. En este mismo artículo se aplica la transformada de Hilbert para detectar la envolvente de señales de tiempo de alta frecuencia con una mejor localización y una resolución óptima. También se demuestra que el cepstrum de energía incrementa la resolución de la detección. Por otro lado, se desarrolla un algoritmo llamado "split spectrum processing (SPP)" que consiste en dividir en rebanadas el espectro de frecuencias de la señal (del defecto) y aplicar la inversa de la transformada de Fourier para mejorar el ratio señal-ruido; esto se materializa mediante la superposición de filtros pasabandas gaussianos con diferentes frecuencias centrales y un ancho de banda absoluto fijo; este algoritmo es muy empleado en materiales muy absorbentes. Se propone, por último, utilizar una función de correlación para determinar la similitud entre dos ecos procedentes de grietas y defectos.

En el año 2008 [7], este mismo autor, junto con otros compañeros, propone la estimación de la señal eco del defecto mediante el algoritmo "expectationmaximization" ( $E M$, en adelante). Como una alternativa a los métodos de mínimos cuadrados, este algoritmo ha sido propuesto para la estimación de parámetros de señales superpuestas en ruido. Los algoritmos $E M$ traducen $M$ ecos superpuestos en $M$ estimaciones de ecos, separadas utilizando conjuntos de datos no observados, y que representan estos últimos un único eco en ruido blanco gaussiano. 
Tras amplia documentación de los métodos hasta ahora existentes, se presentan, en el apartado de metodología, ciertas variantes de éstos y algunos métodos de contribución completamente propia con los que ha estimado el cálculo del retardo y que se pretenden comparar entre sí.

\subsection{PRESENTACIÓN DEL FENÓMENO Y DE LAS VARIABLES DE ESTUDIO}

El HRFV es objeto de estudio desde la década 1960-1970 [2]. Desde entonces, se pretende pueda convertirse en uno de los sustitutos del HA tradicional, pues las estructuras podrían ejecutarse en plazos menores, ya que el proceso de ferrallado sería prescindible o, al menos, conllevaría un tiempo menor que el habitual pues únicamente se necesitaría colocar una cuantía mínima de armadura, ya que las FV estarían proporcionando al hormigón en masa la capacidad a flexotracción que el acero aporta al HA convencional.

Si bien es cierto que aunque, conforme pasa el tiempo, la industria de la construcción establece cada vez más aplicaciones a las FV, aún no se ha logrado implantar el HRFV como competidor directo del HA tradicional, debido a que, entre otras razones, éste último es un material de comportamiento muy conocido y por tanto de máxima garantía y fiabilidad, y a que su coste es inferior al del HRFV con las dosis de fibras hasta ahora empleadas. Por ello, es de interés investigar más sobre el HRFV para conocer mejor las propiedades del mismo [3], optimizarlo y poder aprovechar su potencial.

Hasta nuestros días, se han establecido porcentajes de FV del orden del 3\% en peso con los que se logra, sin duda, HRFV de inmejorable comportamiento estructural. Pero este porcentaje vuelve inviable la construcción de estructuras a base de este tipo de hormigón, puesto que el precio de la FV es muy elevado y encarece mucho el material.

Por todo ello, se ha querido abrir una línea de investigación sobre dosificación del hormigón para intentar reducir la cantidad de FV a incorporar en la fabricación del HRFV, sin detrimento por supuesto de la calidad estructural conseguida con las dosis antes comentadas pero no permisibles desde el punto de vista económico.

Las propiedades mecánicas del HRFV dependen de muchos factores: contenido en FV, relación agua/cemento, porosidad, contenido de arena, orientación de la fibra, curado, etc.

Aquí se estudian diferentes dosificaciones de HRFV, manteniendo constantes las cantidades de todos los componentes salvo de las FV, y variando factores como la longitud de las FV y el curado de las probetas (probetas curadas hasta 7 días y probetas curadas hasta 28 días); todas estas dosificaciones se comparan con una dosificación de referencia, confeccionada a base de HM tradicional.

En este estudio se calculará, mediante técnicas no destructivas, y con la ayuda de los algoritmos propios de cálculo de retardos de ondas, el módulo de elasticidad del HRFV y, con él, la resistencia a compresión, que se comparará con la obtenida de un ensayo normalizado de compresión y que servirá para vislumbrar cuál es el algoritmo que aporta resultados más parecidos al método invasivo descrito.

Por otro lado, el ensayo a flexotracción determinará qué dosis de fibras es la más adecuada. 


\section{METODOLOGIA}

\subsection{MATERIALES Y ESPECÍMENES}

Se han diseñado distintas dosificaciones de HRFV variando el contenido y la longitud de las FV y manteniendo las cantidades del resto de componentes (salvo el plastificante en los casos requeridos), a efectos precisamente de comprobar la influencia de las fibras.

La relación agua/cemento es 0.6 y el contenido por metro cúbico de los componentes es el siguiente: $1736.5 \mathrm{~kg}$ de árido, siendo el $40 \%$ árido grueso $(8 / 12)$ y el $60 \%$ fino $(0 / 5)$; se han utilizado $350 \mathrm{~kg}$ de cemento CEM I $42.5 \mathrm{R}$; por último, se han adicionado $1.92 \mathrm{~kg}$ de aditivo superplastificante Dynamon SP3 (salvo cuando, por necesidades imperiosas de la trabajabilidad del propio hormigón, se vio necesario aumentar hasta $2.30 \mathrm{~kg}$ la dosis de este aditivo, lo que sucedió al emplear los porcentajes mayores de contenido en fibras, es decir, en las dosificaciones 5 y 9; no obstante, este tipo de aditivos no afectan sustancialmente las propiedades mecánicas del hormigón endurecido conseguido).

En el presente estudio se han diseñado diversas dosificaciones (ver tabla 1). Por un lado, se han realizado probetas de HM sin fibras atendiendo a lo especificado bajo el nombre de "Dosificación 1", y que han de servir de referencia al estudiar el HRFV. Por otro lado, se han diseñado cuatro dosificaciones de HRFV utilizando FV cortas, de $12 \mathrm{~mm}$ de longitud, en las proporciones de $0.4 \%, 0.8 \%, 1.1 \%$ y $1.5 \%$, y nombradas como "Dosificación 2", "Dosificación 3", “Dosificación 4" y "Dosificación 5" respectivamente. De la misma manera, se han propuesto dosificaciones con fibras de mayor longitud (36 $\mathrm{mm})$, nombradas como "Dosificación 6", “Dosificación 7", “Dosificación 8" y "Dosificación 9", atendiendo a los mismos porcentajes de contenido en FV escogidos para elaborar las probetas con FV cortas. Señalar que las FV utilizadas se denominan comercialmente ROVING 54/76 2450 y de manera técnica ARC 1453042450.

\begin{tabular}{|c|c|c|c|c|c|c|c|c|c|}
\hline \multirow{2}{*}{ Componente $\left(\mathrm{kg} / \mathrm{m}^{3}\right)$} & \multicolumn{10}{|c|}{ Dosificación } \\
\cline { 2 - 11 } & 1 & 2 & 3 & 4 & 5 & 6 & 7 & 8 & 9 \\
\hline Agua & 210 & 210 & 210 & 210 & 210 & 210 & 210 & 210 & 210 \\
\hline Cemento & 350 & 350 & 350 & 350 & 350 & 350 & 350 & 350 & 350 \\
\hline Fracción 0/5 & 1041,9 & 1041,9 & 1041,9 & 1041,9 & 1041,9 & 1041,9 & 1041,9 & 1041,9 & 1041,9 \\
\hline Fracción 8/12 & 694,6 & 694,6 & 694,6 & 694,6 & 694,6 & 694,6 & 694,6 & 694,6 & 694,6 \\
\hline Aditivo & 1,92 & 1,92 & 1,92 & 1.92 & 2,30 & 1,92 & 1,92 & 1,92 & 2,30 \\
\hline Fibra 12 mm & 0 & 9,2 & 18,4 & 25,3 & 34,5 & 0 & 0 & 0 & 0 \\
\hline Fibra 36 mm & 0 & 0 & 0 & 0 & 0 & 9,2 & 18,4 & 25,3 & 34,5 \\
\hline
\end{tabular}

Tabla 1. Proporciones de mezcla para el hormigón convencional y el HRFV

\begin{tabular}{|c|c|c|c|c|c|c|c|c|c|}
\hline \multirow{2}{*}{ Densidad $\left(\mathrm{kg} / \mathrm{m}^{3}\right)$} & \multicolumn{9}{|c|}{ Dosificación } \\
\cline { 2 - 10 } & 1 & 2 & 3 & 4 & 5 & 6 & 7 & 8 & 9 \\
\hline Curada 7 días & 2415 & 2378 & 2373 & 2362 & 2322 & 2425 & 2405 & 2383 & 2344 \\
\hline Curada 28 días & 2439 & 2399 & 2398 & 2341 & 2306 & 2425 & 2414 & 2422 & 2424 \\
\hline
\end{tabular}

Tabla 2. Densidad de las probetas de hormigón convencional y de HRFV según el tiempo de curado

De cada dosificación se hicieron dos probetas prismáticas de $15 \times 15 \times 60 \mathrm{~cm}$, una de las cuales se conservó en cámara húmeda durante 7 días y la otra durante 28 días. En la tabla 2 se recoge la densidad de cada espécimen, y que se utilizará en el estudio más adelante. 


\subsection{METOdOLOGÍA PARA LA DETERMINACIÓN DEL MÓDULO ELÁSTICO DADO UN ESPECIMEN DE HRFV}

\subsubsection{METODOLOGÍA}

\section{Metodología experimental}

\section{Ondas P}

-Generación: se han generado los siguientes pulsos en cada punto de medida:

\begin{tabular}{|c|c|c|c|c|}
\hline Generación & $\mathrm{N}^{\circ}$ ciclos & Repetición $(\mathrm{ms})$ & Frecuencia $(\mathrm{MHz})$ & Energía $(\mathrm{V})$ \\
\hline Pulso 1 & 1 & 10 & 1 & 10 \\
\hline Pulso 2 & 1 & 10 & 0,5 & 10 \\
\hline Pulso 3 & 1 & 10 & 0,25 & 10 \\
\hline Pulso 4 & 5 & 10 & 1 & 10 \\
\hline Pulso 5 & 5 & 10 & 0,5 & 10 \\
\hline Pulso 6 & 5 & 10 & 0,25 & 10 \\
\hline
\end{tabular}

Tabla 3. Pulsos generados en ondas $P$

-Amplificación: $42 \mathrm{~dB}$

-Transductores: un emisor y un receptor de 0,5 pulgadas de diámetro, frecuencia central de $1 \mathrm{MHz}$, banda ancha

-Preamplificación: $40 \mathrm{~dB}$

-Digitalización: 12 bits, 2000 puntos, 100 microsegundos

Nota: cuando se ha utilizado el equipo portátil de ultrasonidos (Pundit) para medir ondas $\mathrm{P}$, se ha generado un único pulso de un ciclo y con una frecuencia de $54 \mathrm{KHz}$.

\section{Ondas S}

-Generación: se han generado los siguientes pulsos en cada punto de medida:

\begin{tabular}{|c|c|c|c|c|}
\hline Generación & $\mathrm{N}^{\circ}$ ciclos & Repetición $(\mathrm{ms})$ & Frecuencia $(\mathrm{KHz})$ & Energía (V) \\
\hline Pulso 1 & 1 & 10 & 100 & 10 \\
\hline Pulso 2 & 1 & 10 & 50 & 10 \\
\hline Pulso 3 & 1 & 10 & 25 & 10 \\
\hline Pulso 4 & 5 & 10 & 100 & 10 \\
\hline Pulso 5 & 5 & 10 & 50 & 10 \\
\hline Pulso 6 & 5 & 10 & 25 & 10 \\
\hline
\end{tabular}

Tabla 4. Pulsos generados en ondas $\mathrm{S}$

-Amplificación: $42 \mathrm{~dB}$

-Transductores: un emisor y un receptor de 1 pulgada de diámetro, frecuencia central de $100 \mathrm{KHz}$, banda ancha

-Preamplificación: $40 \mathrm{~dB}$

-Digitalización: 12 bits, 2000 puntos, 200 microsegundos

Para generar los pulsos en vacío tanto con ondas $\mathrm{P}$ como con $\mathrm{S}$ se ha utilizado la misma configuración descrita para cada una de estas ondas aplicadas sobre el espécimen pero en este caso prescindiendo del preamplificador y utilizando una energía de $100 \mathrm{mV}$. 
Pese a haber generado todos los pulsos anteriormente descritos, no se han tenido en cuenta todos ellos para realizar el estudio, puesto que algunos no aportaban señales con información; en concreto, los pulsos desestimados han sido los producidos con ondas $\mathrm{S}$ a 50 y a $25 \mathrm{KHz}$.

\section{Metodología de cálculo del retardo}

Se han empleado cuatro metodologías de cálculo del retardo, y todas ellas se exponen a continuación.

\subsubsection{TEORÍA DE LA SEÑAL. COMPARACIÓN DE ALGORITMOS DE CÁlCULO DE RETARDO DE ONDAS}

\section{Algoritmo por "Gates" (ventanas) de los equipos comerciales convencionales de ultrasonidos}

Los equipos comerciales convencionales de ultrasonidos tienen implementado el mismo sistema para la determinación del retardo. Este método es conocido ampliamente por la denominación de sistema por "gates".

Consiste en estimar el retardo como el momento en el que la señal sobrepasa un determinado umbral de voltaje, bien el que traen implementado por defecto algunos equipos de ultrasonidos, bien el que el usuario ajusta según sus requerimientos en los aparatos más complejos.

Así pues, cuando la señal, expresada en términos de voltaje, alcanza un determinado umbral, el dispositivo devuelve el tiempo que ha trascurrido desde que se emite el pulso hasta que se alcanza el umbral, y que es lo que se denomina como retardo.

\section{Determinación visual del retardo a partir de las gráficas de las señales}

Este método de cálculo de retardo y los dos siguientes se aplican sobre las señales producidas con el equipo ultrasónico del laboratorio de END de la Universidad de Granada.

El equipo de ultrasonidos arriba mencionado consiste en un generador de ondas conectado a un ordenador y a un osciloscopio, además de un amplificador y un preamplificador de ondas con objeto de mantener la intensidad suficiente en las señales como para poder ser tratadas posteriormente.

Mediante la sincronía creada entre el ordenador y el generador de ondas a través de un algoritmo computacional implementado en Matlab que permite abrir y cerrar comunicación con dicho generador de ondas, éste último genera una señal, emitida por el transductor emisor sobre el espécimen. Cuando este pulso atraviesa el elemento de ensayo, el transductor receptor recoge la señal resultante, que es guardada, en voltaje, en el ordenador, y analizada de diversas maneras: métodos 2,3 y 4 de este apartado.

El método 2 consiste en la estimación del retardo a partir de la visualización de la señal en pantalla. Haciendo uso del zoom, y fijándose en la forma de la señal, es posible detectar, de una forma más o menos aproximada, el momento en que la señal llega al transductor receptor tras pasar por el cuerpo en estudio. 
El mismo procedimiento de cálculo de retardo se realiza con los dos transductores en contacto, sin espécimen de por medio.

Restando el retardo producido a través del espécimen y el que ocurre en el vacío, se elimina el posible desajuste de salida de la señal por el transductor emisor y se obtiene de forma más precisa el tiempo que tarda en la señal en atravesar el espécimen.

\section{Algoritmo "Delay"}

Este algoritmo toma como el comienzo de la señal el momento en que ésta sobrepasa un cierto umbral de energía.

No obstante, antes de devolver el comienzo de la señal, hace un tratamiento de la misma. En primer lugar, quita el efecto del principio haciendo nulos los primeros valores de la señal y la centra en cero. Tras ello, hace la transformada de Fourier de la señal para conseguir el espectro, espectro que suaviza, normaliza y al que añade bajas frecuencias. A continuación, realiza un filtro del espectro para inferir unos nuevos coeficientes de Fourier. Ahora, mediante la inversa de la transformada de Fourier, se obtiene la señal ya filtrada, señal a la que se le aplica un filtro de paso bajo, es decir, se dejan pasar las frecuencias bajas, quitando las altas, pues estas últimas son ruido.

El siguiente paso es normalizar la señal, para hacerla independiente del material.

Por último, encuentra el instante en que la señal supera la unidad, es decir, encuentra el retraso de la señal.

El algoritmo realiza el procesado descrito también sobre la señal medida en vacío, y halla el retardo en vacío.

Restando el retardo de la señal como consecuencia de pasar a través del espécimen y el retardo de ésta en el vacío, se obtiene el retardo realmente buscado.

Lo anterior, por tanto, puede resumirse en:

Filtrado basado en información en frecuencia

- Enventanado del $90 \%$ inicial para eliminar el efecto en el inicio de la señal

- Restablecimiento del cero

- Espectro de Fourier suavizado mediante moving average

- Normalización y adición de frecuencias bajas

- Filtrado de paso suavizado mediante moving average

- Eliminación del acoplamiento electrónico (eliminación del pulso inicial)

- Aplicación a excitación y a recepción

Búsqueda del inicio de subida de energía de la señal

- Cálculo de umbral basado en energía RMS de señal filtrada

Posprocesado

- Cálculo de gradiente de retardos

- Suavizado del gradiente mediante moving average

- Cálculo del error mediante desviación típica por teoría de errores con 3 muestras 


\section{Algoritmo "Delay cross-correlation trigger"}

Se trata de un algoritmo de cálculo de retardo combinando la correlación cruzada con la búsqueda por umbrales de energía, pero no sobre la señal, sino sobre la propia función de correlación. Busca valores de retardo para varios umbrales y luego estima uno con un criterio a priori no demasiado bueno, la moda, pero que parece que funciona admisiblemente bien.

Al igual que en el método anterior, antes de hallar el instante en que comienza verdaderamente la señal, se hace un tratamiento de la misma.

Un primer paso es quitar el efecto del principio haciendo nulos los primeros valores de la señal y centrar la señal en cero.

Después, se filtra la señal que contiene información de energía. Se utiliza la transformada de Fourier de la señal para conseguir el espectro, espectro que se suaviza, se normaliza y al que se le añaden bajas frecuencias. Se realiza en este momento un filtro del espectro con objeto de inferir unos nuevos coeficientes de Fourier. Ahora, mediante la inversa de la transformada de Fourier, se obtiene la señal ya filtrada.

Esto se realiza tanto para la señal obtenida cuando se utiliza el espécimen como para la señal que se tiene sin haberlo empleado.

Tras esto, se calcula la correlación cruzada entre la señal que ha atravesado el espécimen y la que ha hecho lo propio en el vacío.

A la correlación cruzada se le aplica un filtro de paso bajo, es decir, que deja pasar las frecuencias bajas, quitando las altas, pues estas últimas son ruido. Es de resaltar que se definen tantos filtros de paso bajo como frecuencias de excitación se quieran ensayar.

En este momento, se definen una serie de umbrales que cortarán la correlación cruzada normalizada, y que llevarán asociados una serie de retardos.

Finalmente, el retardo más frecuente (es decir, la moda) es el buscado.

El proceso completo queda, por tanto, como sigue:

Filtrado basado en información en frecuencia

- Enventanado del $90 \%$ inicial para eliminar el efecto en el inicio de la señal

- Restablecimiento del cero

- Espectro de Fourier suavizado mediante moving average

- Normalización y adición de frecuencias bajas

- Filtrado de paso suavizado mediante moving average

- Eliminación del acoplamiento electrónico (eliminación del pulso inicial)

- Aplicación a excitación y a recepción

Búsqueda del inicio de subida de energía de la señal

- Cálculo de la correlación cruzada entre la señal con y sin espécimen

- Cálculo de umbral basado en energía RMS (en términos de correlación cruzada) de señal filtrada 
Posprocesado

- Cálculo de gradiente de retardos

- Suavizado del gradiente mediante moving average

- Cálculo del error mediante desviación típica por teoría de errores con 3 muestras

\subsubsection{ULTRASONIDOS. CÁLCULO DE MÓDULO ELÁSTICO}

La perturbación se propaga a través de tres ondas diferentes. Las ondas $\mathrm{P}$ o de presión, donde el movimiento de la partícula es paralelo a la dirección de propagación. Las ondas $\mathrm{S}$ o transversales en las que, como su nombre indica, la propagación de la partícula es perpendicular a la dirección de propagación de la onda. $\mathrm{Y}$ las ondas $\mathrm{R}$, que se propagan lejos de la perturbación a través de la superficie [4]. En este estudio se han utilizado las ondas $\mathrm{P}$ y las ondas $\mathrm{S}$, conseguidas mediante sus correspondientes transductores.

Atendiendo a la expresión siguiente, se puede relacionar el módulo elástico de un material isótropo con la velocidad de la onda de presión a través de otras constantes elásticas y físicas del material, tal y como sigue:

$$
c_{p}=\sqrt{\frac{E(1-v)}{\rho(1+v)(1-2 v)}}
$$

Siendo

E módulo elástico

$v$ coeficiente de Poisson

$\rho$ densidad volumétrica

Existen varios métodos de ondas de presión. En este estudio se ha utilizado el método de transmisión directa. Es uno de los métodos más antiguos de END para hormigón y está basado en medir el tiempo de viaje sobre un camino de longitud conocida de un pulso de una onda de compresión ultrasónica. Este método se conoce como método de transmisión o método de la velocidad del pulso ultrasónico.

La metodología es la siguiente: se coloca un transductor de transmisión en una cara del cuerpo en estudio y otro transductor, éste de recepción, en la cara opuesta. Los transductores contienen elementos cerámicos piezoeléctricos que cambian de dimensión cuando se les aplica un voltaje y viceversa. Así pues, al transductor emisor se le aplica un voltaje; a consecuencia de este voltaje, el transductor vibra a su frecuencia natural y esta vibración transmite un pulso de presión sobre el cuerpo en estudio. En ese mismo instante, se pone en marcha un reloj electrónico de alta precisión. Este pulso de presión se propaga a través del cuerpo y llega al emisor receptor, que se deforma y convierta esa deformación en voltaje, apagando el cronómetro. Finalmente, se representa el voltaje.

Por otro lado, la expresión que incorpora la velocidad de las ondas S es la siguiente: 


$$
c_{S}=\sqrt{\frac{E}{2 \rho(1+v)}}
$$

Partiendo de las definiciones dadas para la velocidad de las ondas $\mathrm{P}$ y $\mathrm{S}$, se puede formular una expresión que relaciona ambas velocidades y que no depende de $\mathrm{E}$, la variable que quiere hallarse, y que queda como sigue:

$$
c_{p}{ }^{2}=2 c_{s}{ }^{2} \frac{(1-v)}{(1-2 v)}
$$

Haciendo uso de esta expresión se halla el coeficiente de Poisson. Obtenido éste, se calcula el módulo de elasticidad del material con sólo sustituir en cualquiera de las fórmulas para la velocidad de las ondas (P o S).

\subsubsection{TEORÍA DE ERRORES}

La teoría de errores (propagation of uncertainty) consiste en tener en cuenta el efecto de los errores de las variables que intervienen en las funciones que se utilizan para realizar el cálculo de una determinada variable.

Cuando las variables son los valores de medidas experimentales, dichas variables presentan incertidumbres inherentes debidas a las limitaciones de los propios instrumentos de medida (por ejemplo, la precisión). Todas estas incertidumbres asociadas a cada variable experimental entran en juego en el cálculo con cada expresión que se utiliza.

Una manera habitual de expresar la incertidumbre es en términos de desviación estándar, es decir, en términos de la raíz cuadrada positiva de la varianza. Así pues, toda variable se expresa normalmente como $x+\sigma$, es decir, una dupla compuesta por la media de la variable y la desviación estándar asociada a la misma. Ambos parámetros, media y desviación típica, han sido obtenidos para cada variable utilizando los resultados correspondientes a las tres medidas realizadas en cada punto de estudio.

El cálculo de la media es de sobra conocido por todos. El cálculo de la desviación estándar depende de si la variable es experimental o de si viene definida por una función. Cuando la variable es experimental, tal y como se ha tratado en este estudio la densidad del material y el espesor del elemento de ensayo, el cálculo de la desviación estándar es el habitual. Cuando la variable viene expresada como una función en la que intervienen otras variables mediante una combinación no lineal, y todas ellas independientes entre sí, el cálculo puede hacerse como propone el NIST (National Institute of Standards and Technology), que se deduce de la linearización de la función mediante una expansión en serie de Taylor de primer orden, y que se expresa como sigue:

$$
\sigma_{f}=\sqrt{\left(\frac{\partial f}{\partial x}\right)^{2} \sigma_{x}^{2}+\left(\frac{\partial f}{\partial y}\right)^{2} \sigma_{y}^{2}+\left(\frac{\partial f}{\partial z}\right)^{2} \sigma_{z}^{2}+\cdots}
$$

Siendo $f$ la función que permite el cálculo de la variable en estudio (en este estudio, la velocidad de las ondas $P$, de las ondas $S$, el coeficiente de Poisson y el módulo de 
elasticidad), y siendo $x, y, z, \ldots$ las variables tanto experimentales como halladas mediante expresiones matemáticas que intervienen en la expresión de la función.

Es importante tener en cuenta que esta fórmula está basada en las características lineales del gradiente de la función y, por lo tanto, es una buena estimación para la desviación típica de dicha función con tal de que las desviaciones típicas de las variables que intervienen sean pequeñas comparadas con las derivadas parciales.

$\mathrm{Si}$, además, la distribución de probabilidad estadística de la variable es conocida, o puede ser asumida, es posible hallar el intervalo de confianza para delimitar cuál es la región dentro de la cual puede encontrarse el verdadero valor de la variable.

\subsection{VALIDACIÓN MEDIANTE TÉCNICAS DESTRUCTIVAS}

El módulo de elasticidad que se pretende obtener a través de la formulación de ultrasonidos, puede validarse mediante procedimientos tanto destructivos como no invasivos.

En este caso, se han utilizado para la validación los resultados de los ensayos de compresión y de flexotracción, y que se expresan en la siguiente tabla. Una vez obtenido el módulo elástico a través de la formulación de ultrasonidos, no queda más que convertirlo de dinámico a estático y aplicar la expresión contenida en la EHE 2008 que relaciona dicho módulo con la resistencia a compresión, y que viene dada por:

$$
E=10000 * \sqrt[3]{f_{c m}}
$$

Siendo

$E$ módulo elástico $(\mathrm{MPa})$

$f_{c m}$ resistencia media a compresión $(\mathrm{MPa})$

\begin{tabular}{|c|c|c|c|c|c|c|c|c|c|}
\hline $\begin{array}{c}\text { Resistencia } \\
(\mathrm{MPa})\end{array}$ & \multicolumn{10}{|c|}{ Dosificación } \\
\cline { 2 - 10 } & 1 & 2 & 3 & 4 & 5 & 6 & 7 & 8 & 9 \\
\hline Compresión & 32,3 & 33,0 & 31,2 & 28,0 & 17,1 & 28,7 & 31,8 & 30,3 & 30,4 \\
\hline Flexotracción & 5,6 & 5,1 & 5,4 & 5,5 & 4,8 & 4,8 & 5,2 & 5,2 & 5,6 \\
\hline
\end{tabular}

Tabla 5. Resistencia a flexotracción y a compresión de las distintas dosificaciones propuestas

En la tabla anterior puede apreciarse que, conforme aumenta la dosis de FV (tanto corta como larga), la resistencia a compresión disminuye y a flexotracción aumenta.

Se han de destacar, no obstante, varias observaciones. La primera es relativa a los resultados de la primera dosificación. El valor de compresión es menor que el que desprende la dosificación 2, con fibras, y el de flexotracción es mayor, resultados ambos que parecen poco lógicos (más si cabe cuando el resto de la tabla se encuentra en completa sintonía con los resultados que cabría esperar de la teoría sobre el HRFV). Además, debe notarse que la diferencia es sumamente pequeña y estos resultados pueden deberse simplemente a la variabilidad que el hormigón presenta per sé. Por último, destacar que es probable que el valor de resistencia a flexotracción de la dosificación 5 no haya seguido el orden creciente con el aumento de FV porque dicha 
dosificación presentó una consistencia muy seca que, a buen seguro, afectó a las propiedades mecánicas del hormigón.

\section{RESULTADOS Y DISCUSION}

\subsection{PROCESO Y ANÁLISIS DE DATOS}

\subsubsection{INTRODUCCIÓN}

Son muchas las variables que se ha visto conveniente estudiar puesto que se considera pueden tener influencia en las variables verdaderamente objeto de este estudio.

Especial interés se ha mostrado por estudiar la influencia del método de determinación del retardo de ondas $P$ en el cálculo del módulo de elasticidad; también se ha visto interesante estudiar la influencia que puede tener excitar con ondas $\mathrm{P}$ de diferentes frecuencias, e incluso excitar con un único ciclo, o con un señal compuesta de varios ciclos. Por otro lado, se ha prestado especial atención a las consecuencias que puede provocar el tiempo de curado de las probetas. E incluso se ha expresado la evolución en el tiempo de una variable tan importante como el módulo elástico, para reflejar el comportamiento del material objeto de estudio.

\subsubsection{RETARDO DE ONDAS P Y MÓDULO DE YOUNG}

\section{Retardo de las ondas $P$}

- Burst period: 1 ciclo

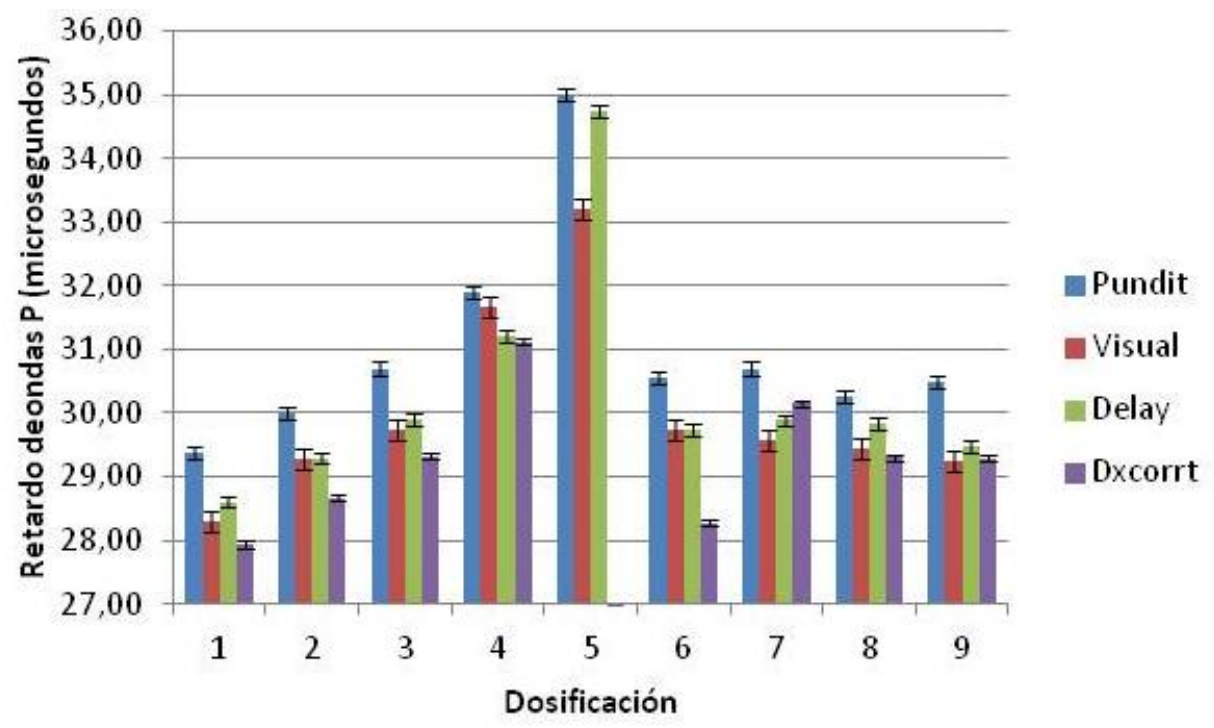

Figura 1. Valores del retardo de ondas $P$ a través del espécimen frente al método ultrasónico de determinación de retardo 


\section{- Burst period: 5 ciclos}

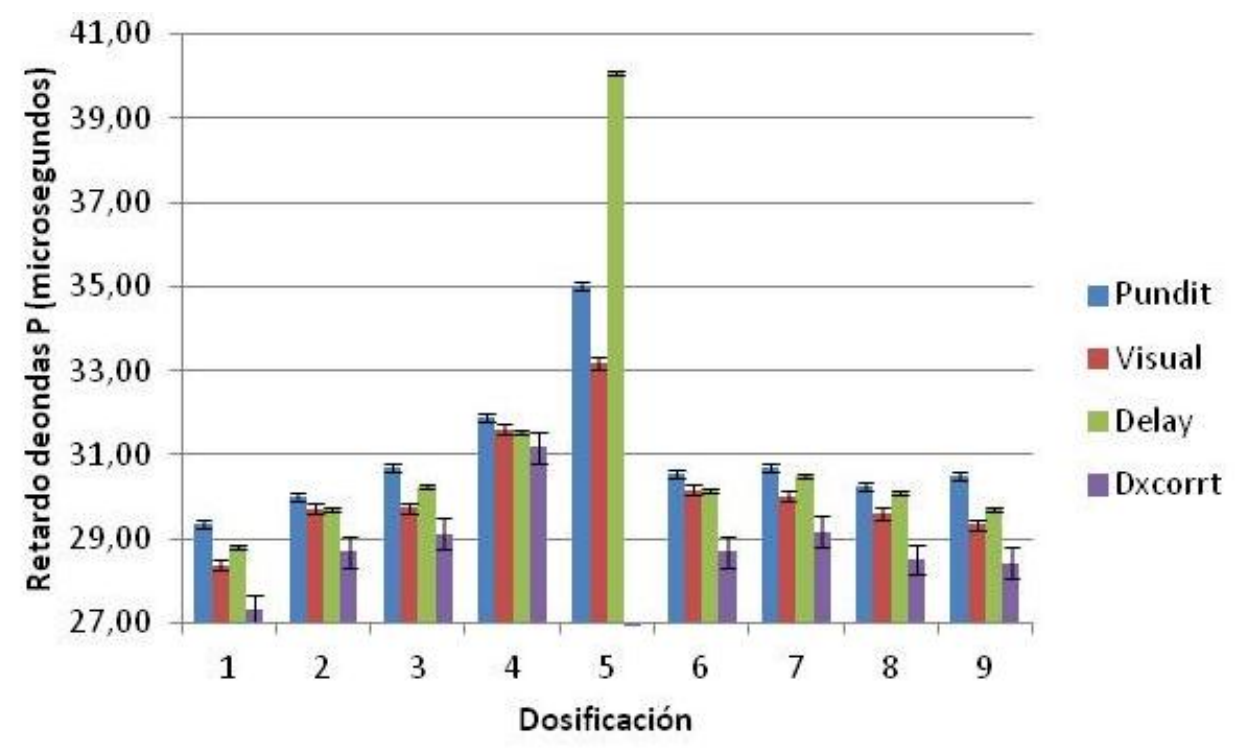

Figura 2. Valores de retardo de ondas $\mathrm{P}$ a través del espécimen para distintos métodos ultrasónicos de determinación de retardo

\section{Módulo de elasticidad}

\section{- Burst period: 1 ciclo}

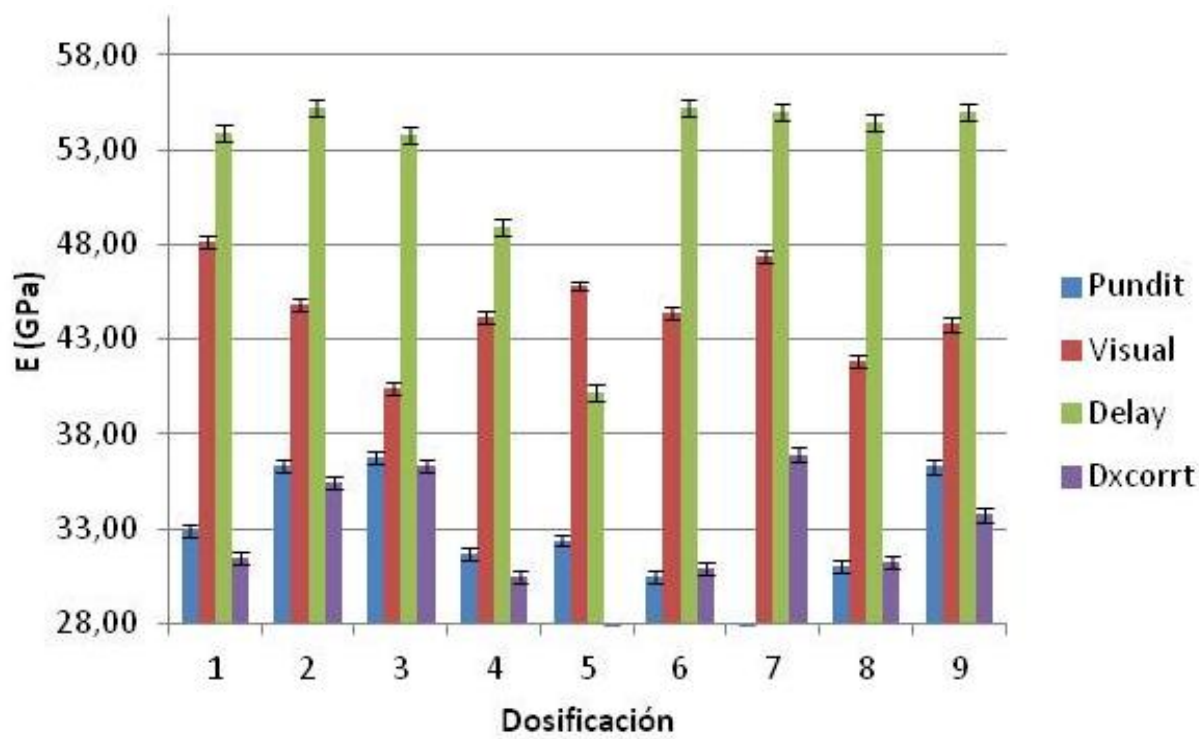

Figura 3. Dependencia del módulo elástico frente al método ultrasónico de determinación de retardo de las ondas de cuerpo 
- Burst period: 5 ciclos

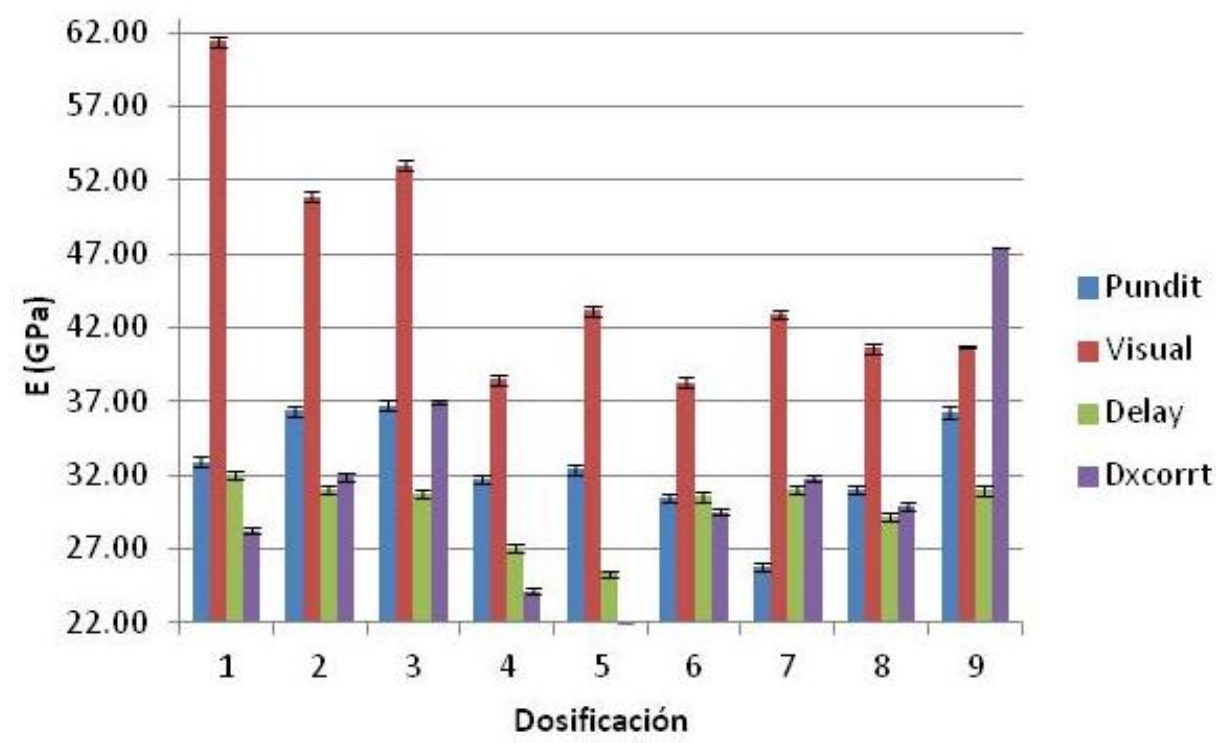

Figura 4. Dependencia del módulo elástico frente al método ultrasónico de determinación de retardo de las ondas de cuerpo

\subsubsection{IDONEIDAD DEL MÉTODO}

Para vislumbrar qué método de los cuatro propuestos reflejaría mejor las características objeto de estudio del HRFV, se ha realizado un estudio comparativo entre la resistencia a compresión que se puede deducir a partir de estos métodos y la resistencia a compresión obtenida mediante el ensayo a compresión normalizado según UNE sobre probetas cilíndricas de $15 \mathrm{~cm}$ de diámetro y $30 \mathrm{~cm}$ de altura.

\section{- Burst period: 1 ciclo}

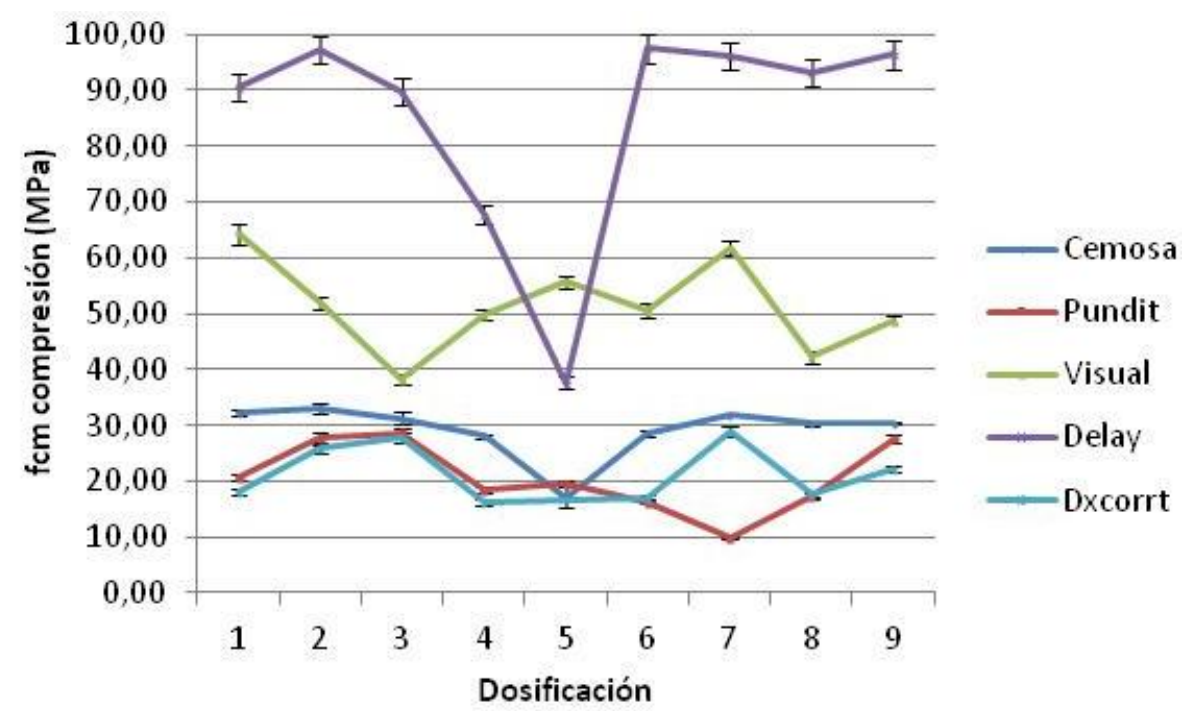

Figura 5. Comparación de métodos de cálculo de retardo a través de la resistencia a compresión 
- Burst period: 5 ciclos

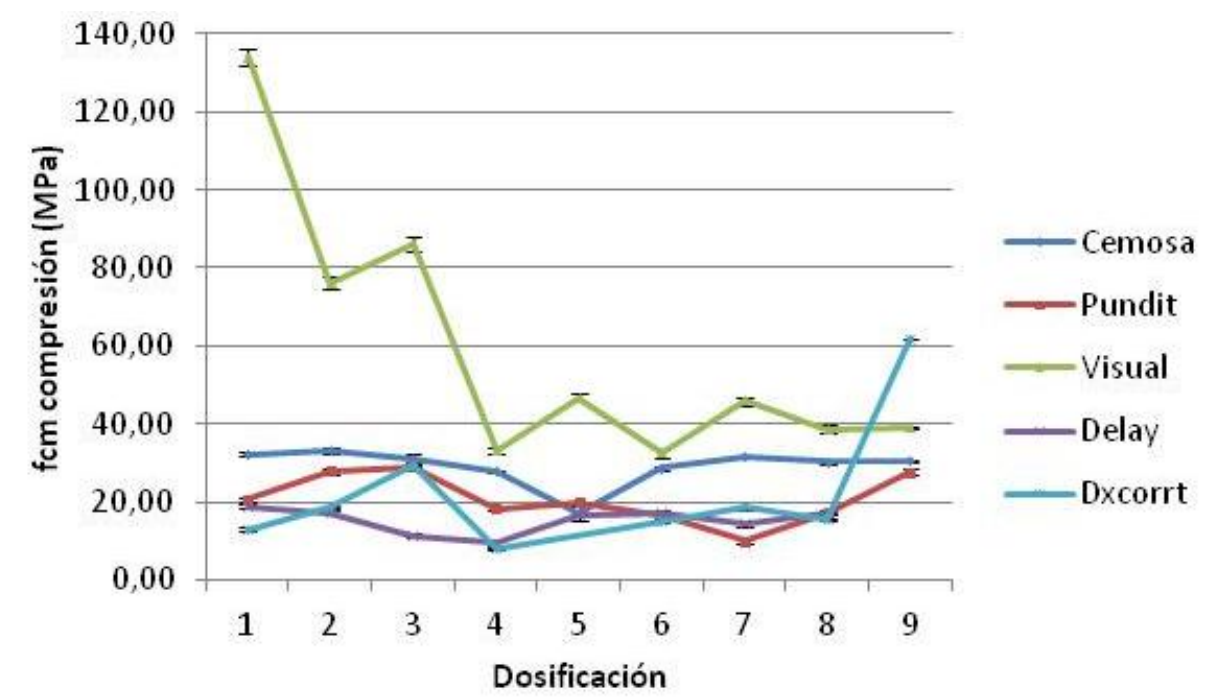

Figura 6. Comparación de métodos de cálculo de retardo a través de la resistencia a compresión

De la observación de las gráficas anteriores se deducen varias conclusiones. En primer lugar, los pulsos generados a partir de 5 ciclos proporcionan valores de resistencia a compresión más próximos a los obtenidos en el ensayo a compresión.

Por otro lado, puede apreciarse que, salvo el método basado en la observación visual de las señales, el resto de métodos proporcionan unos resultados parecidos entre sí y, lo que es más importante, centrados alrededor de los resultados obtenidos en el ensayo destructivo.

De lo anterior, se decide seguir el estudio adelante aplicando todos los métodos propuestos (incluido el visual, pese a intuir que su fiabilidad es menor que la del resto) y observar los resultados que cada uno de ellos desprenden.

\subsubsection{INFLUENCIA DE LAS FIBRAS DE VIDRIO EN EL MÓDULO ELÁSTICO}

\section{Fibras de vidrio cortas $(12 \mathrm{~mm})$}

- Burst period: 1 ciclo

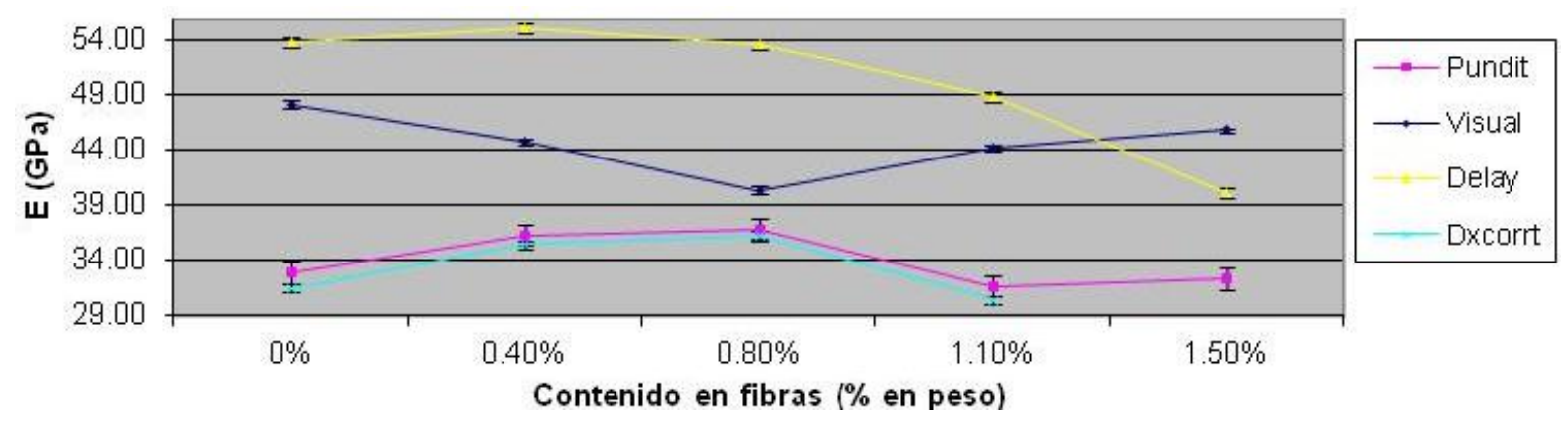

Figura 7. Influencia del contenido en fibra de vidrio en el módulo elástico 


\section{- Burst period: 5 ciclos}

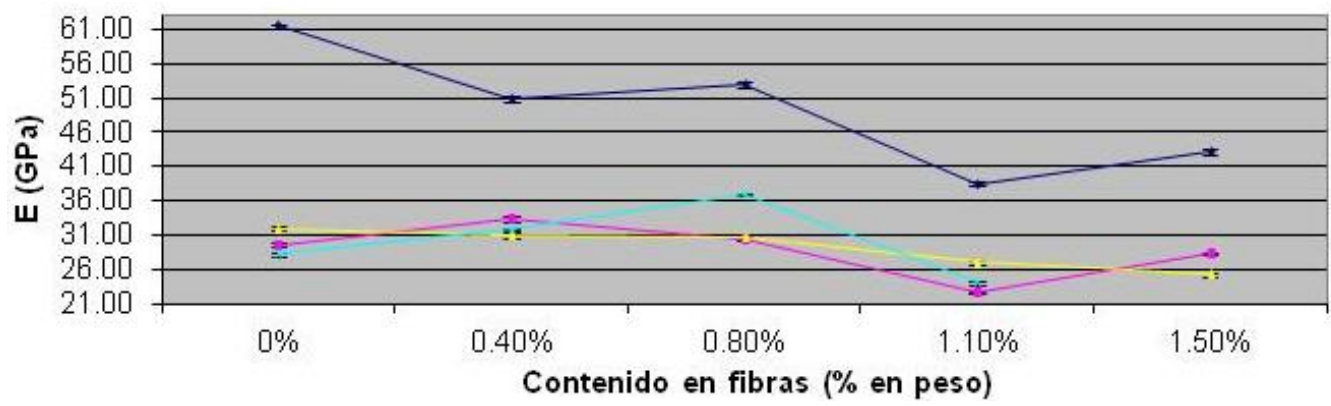

Figura 8. Influencia del contenido en fibra de vidrio en el módulo elástico

\section{Fibras de vidrio largas $(36 \mathrm{~mm})$}

\section{- Burst period: 1 ciclo}
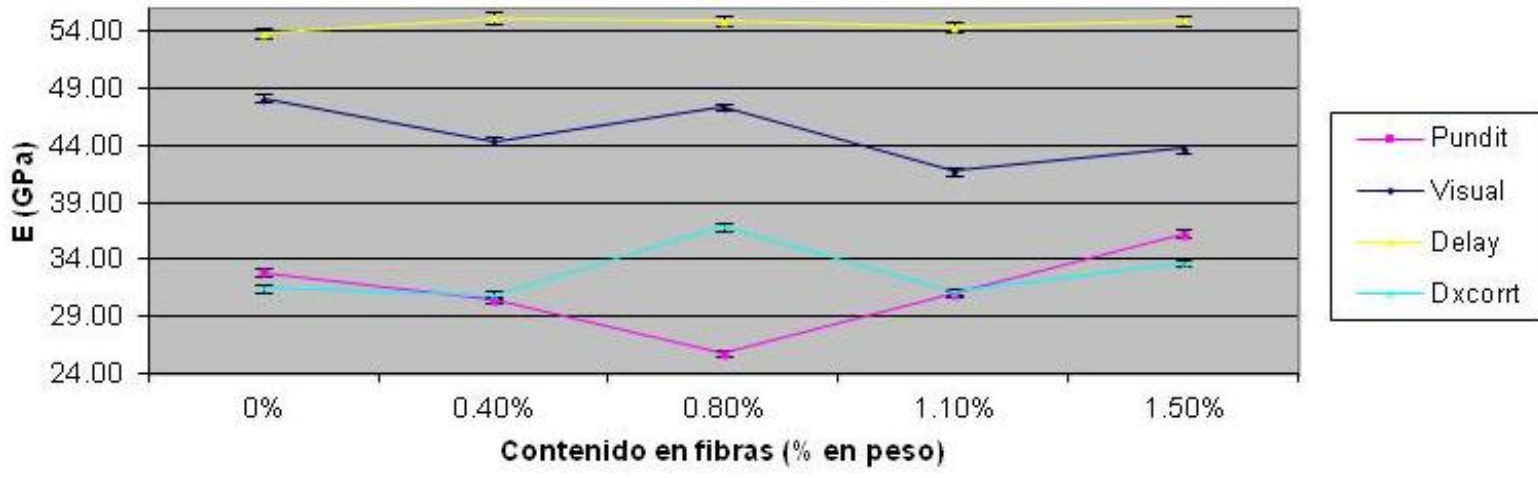

Figura 9. Influencia del contenido en fibra de vidrio en el módulo elástico

\section{- Burst period: 5 ciclos}
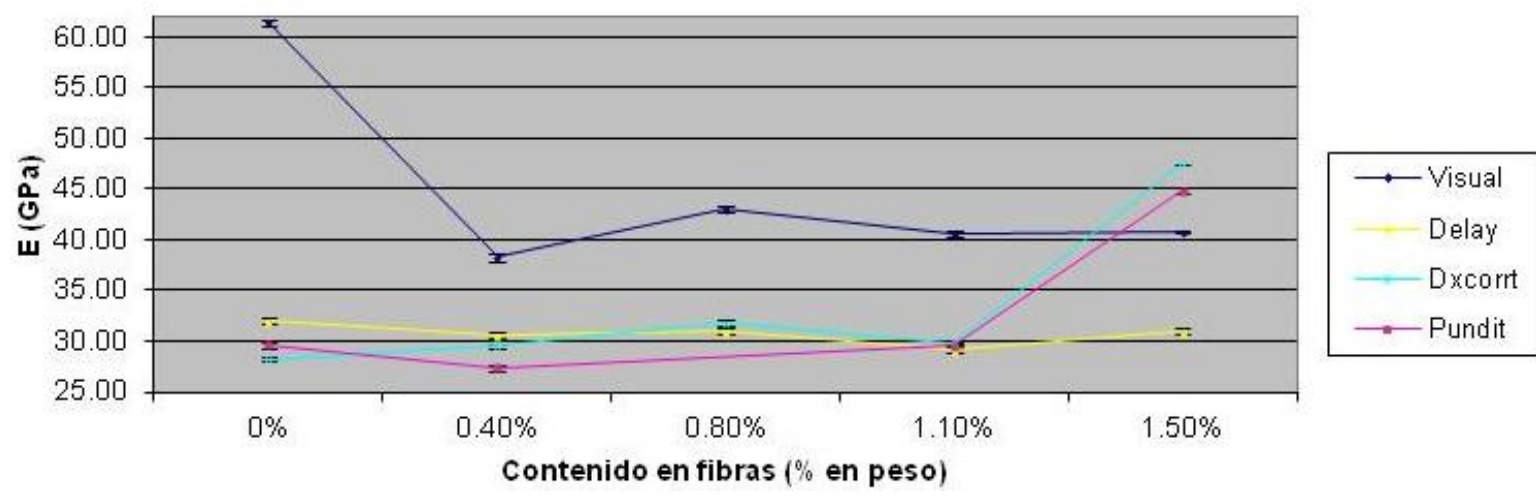

Figura 10. Influencia del contenido en fibra de vidrio en el módulo elástico 


\subsubsection{INFLUENCIA DEL TIEMPO DE CURADO EN EL MÓDULO ELÁSTICO}

\section{A una edad determinada}

\section{- Burst period: 1 ciclo}

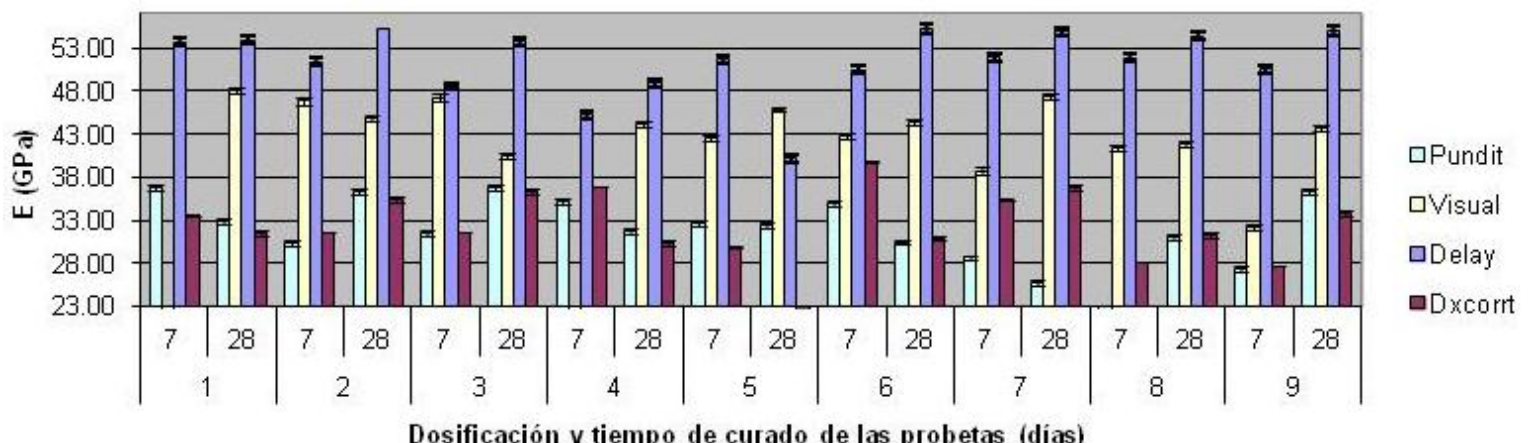

Figura 11. Influencia del tiempo de curado en el módulo elástico

- Burst period: 5 ciclos

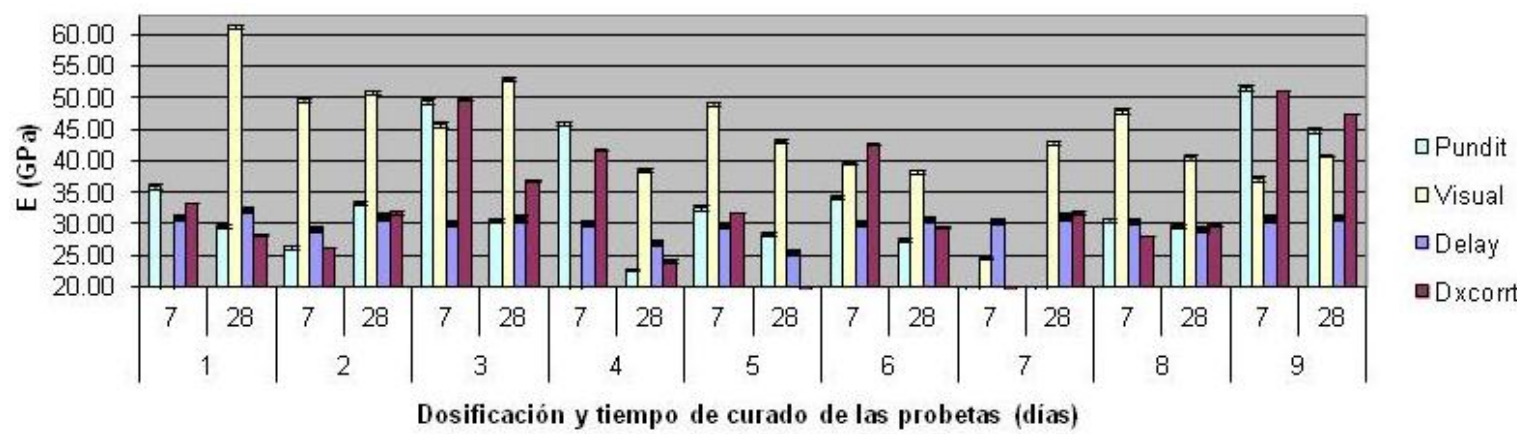

Figura 12. Influencia del tiempo de curado en el módulo elástico

\section{Evolución en el tiempo}

\section{- Burst period: 1 ciclo}
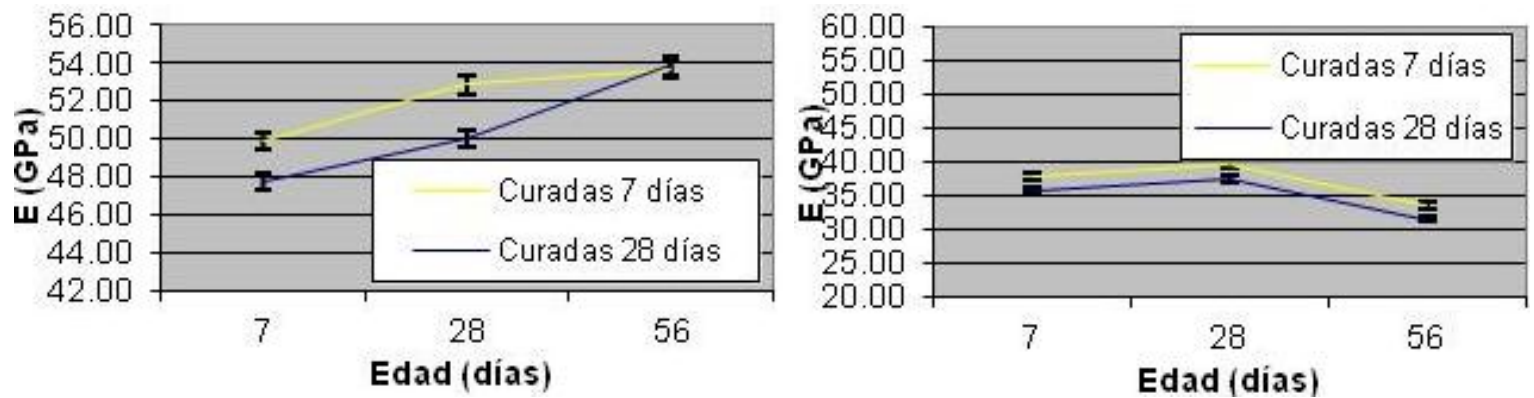

Figura 13. Influencia del tiempo de curado sobre la evolución del módulo elástico según el algoritmo Delay en la figura de la izquierda y según el Dxcorrt en la de la derecha - Dosificación 1 

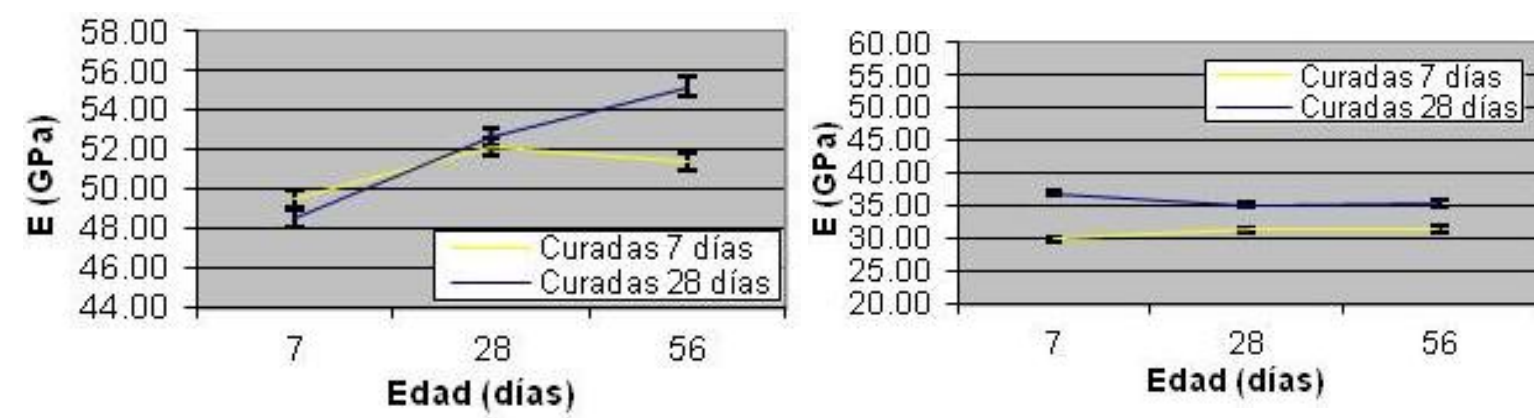

Figura 14. Influencia del tiempo de curado sobre la evolución del módulo elástico según el algoritmo Delay en la figura de la izquierda y según el Dxcorrt en la de la derecha - Dosificación 2
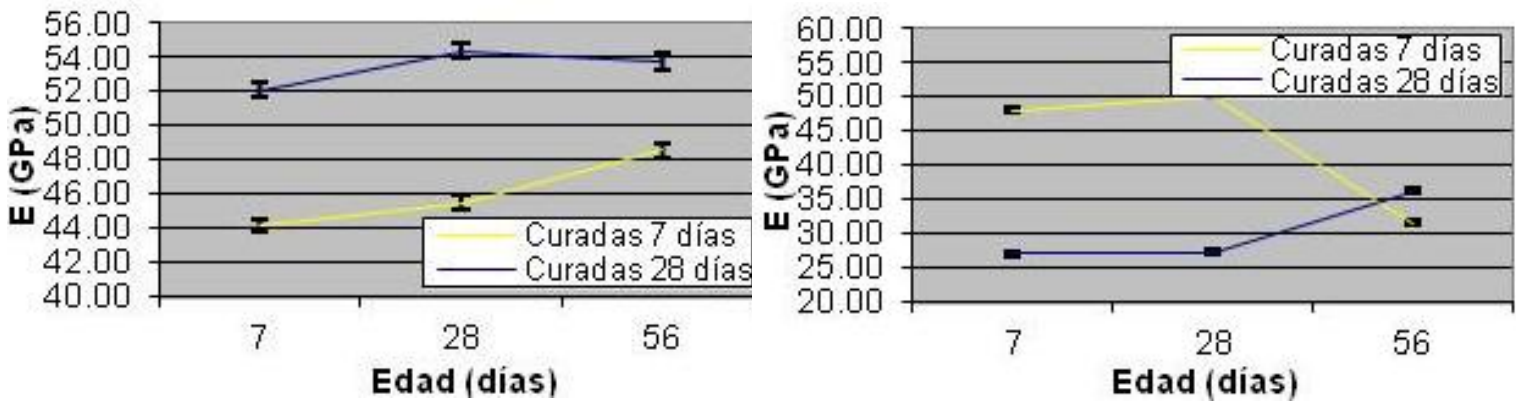

Figura 15. Influencia del tiempo de curado sobre la evolución del módulo elástico según el algoritmo Delay en la figura de la izquierda y según el Dxcorrt en la de la derecha - Dosificación 3
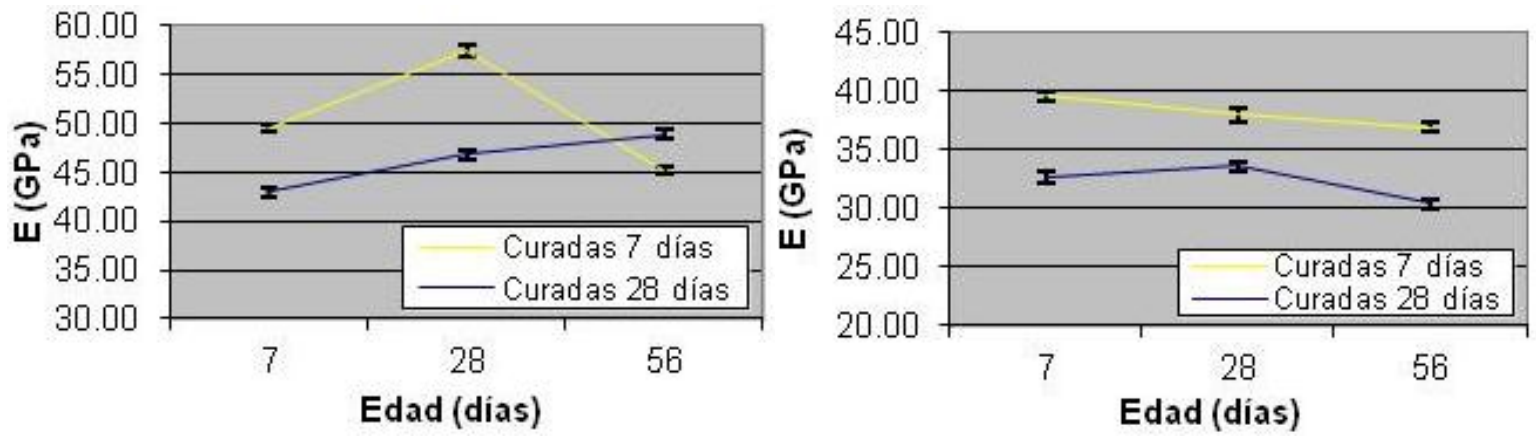

Figura 16. Influencia del tiempo de curado sobre la evolución del módulo elástico según el algoritmo Delay en la figura de la izquierda y según el Dxcorrt en la de la derecha - Dosificación 4
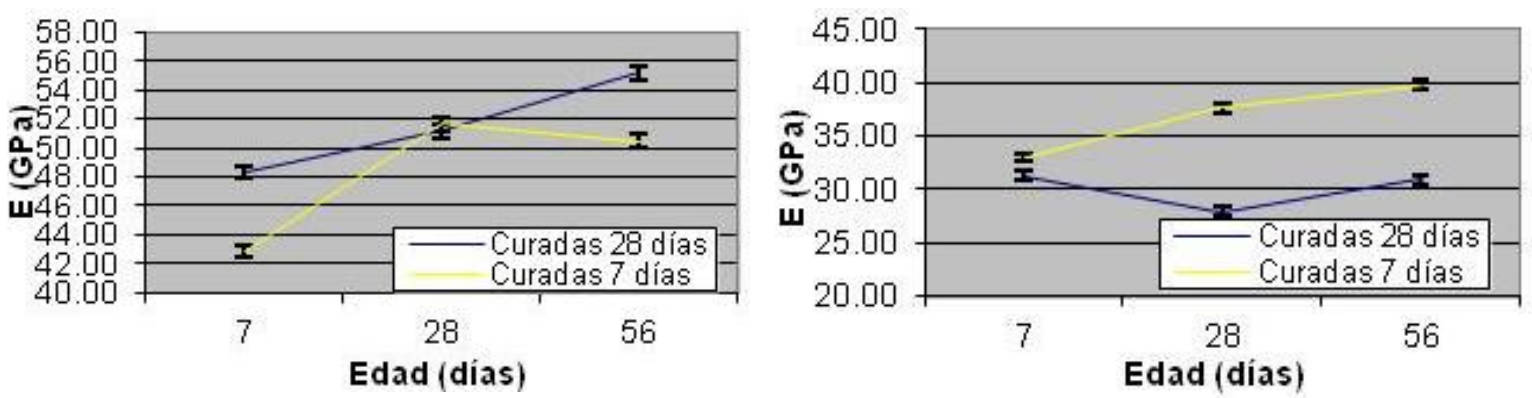

Figura 17. Influencia del tiempo de curado sobre la evolución del módulo elástico según el algoritmo Delay en la figura de la izquierda y según el Dxcorrt en la de la derecha - Dosificación 6
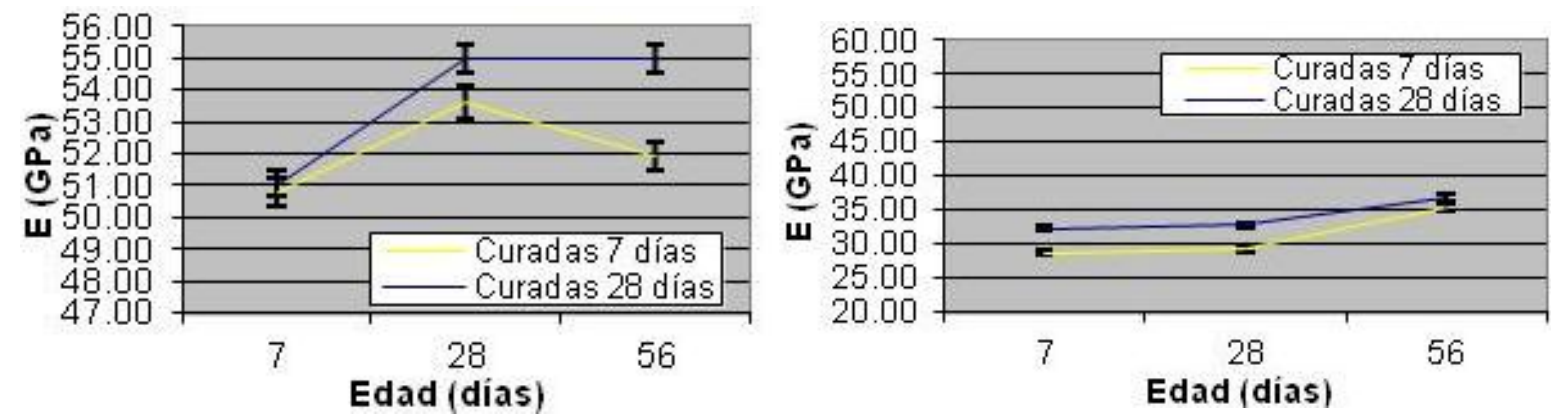

Figura 18. Influencia del tiempo de curado sobre la evolución del módulo elástico según el algoritmo Delay en la figura de la izquierda y según el Dxcorrt en la de la derecha - Dosificación 7 

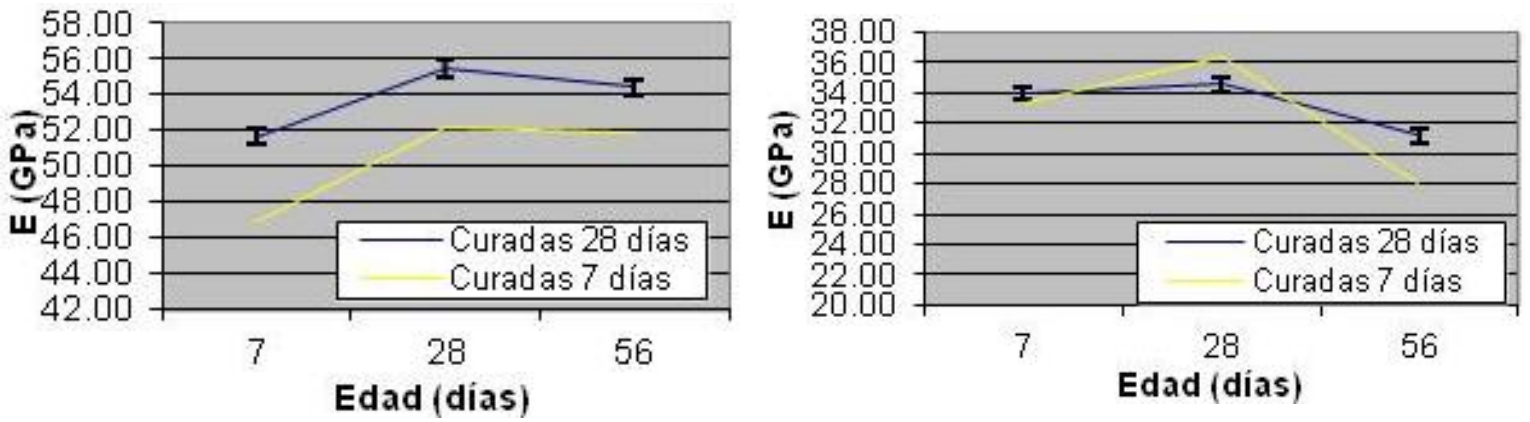

Figura 19. Influencia del tiempo de curado sobre la evolución del módulo elástico según el algoritmo Delay en la figura de la izquierda y según el Dxcorrt en la de la derecha - Dosificación 8

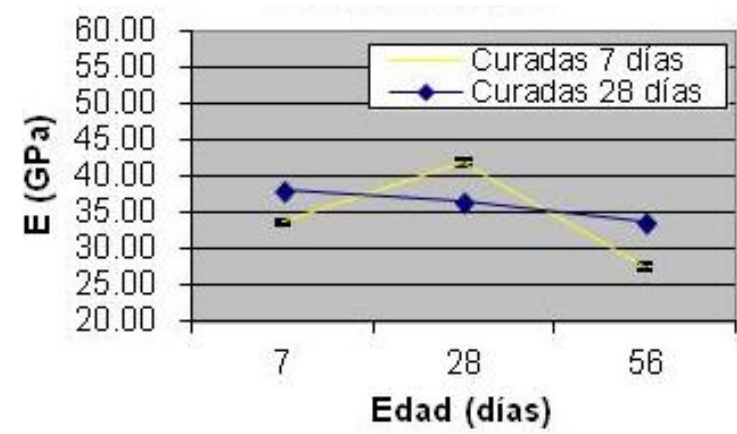

Figura 20. Influencia del tiempo de curado sobre la evolución del módulo elástico según el algoritmo Dxcorrt - Dosificación 9
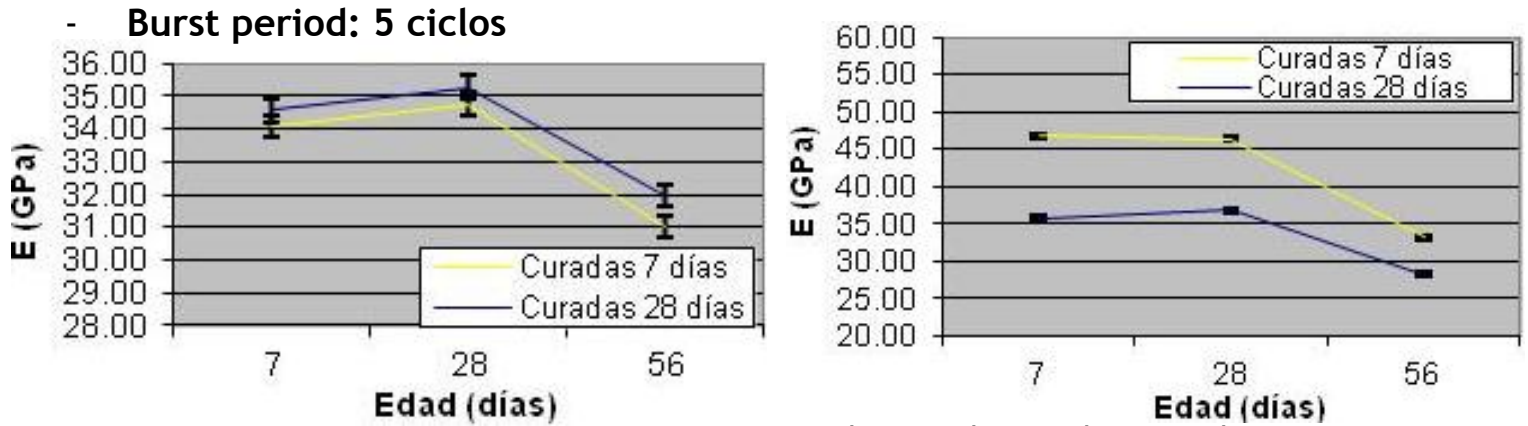

Figura 21. Influencia del tiempo de curado sobre la evolución del módulo elástico según el algoritmo Delay en la figura de la izquierda y según el Dxcorrt en la de la derecha - Dosificación 1
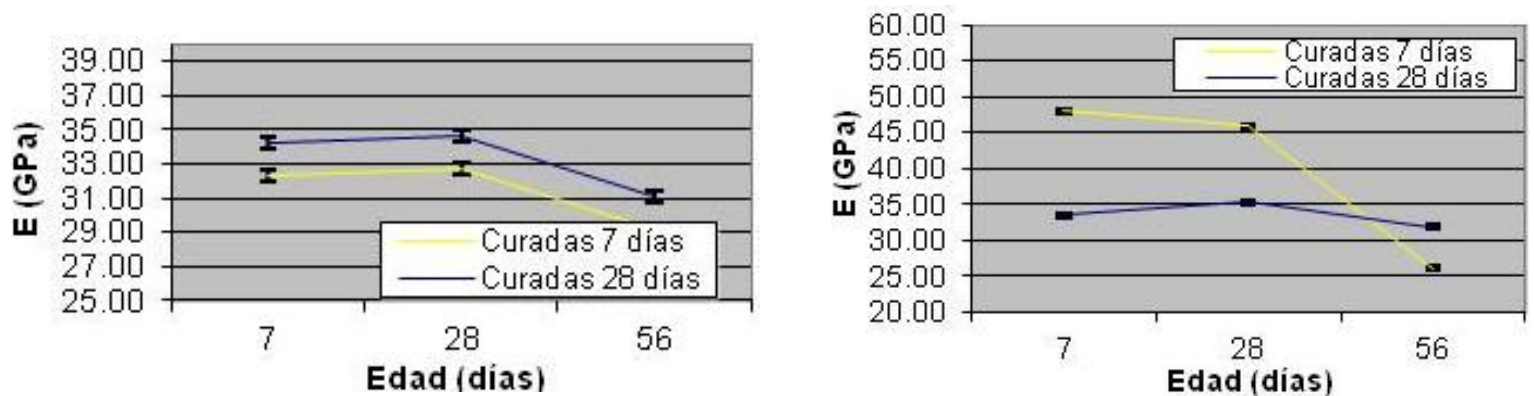

Figura 22. Influencia del tiempo de curado sobre la evolución del módulo elástico según el algoritmo Delay en la figura de la izquierda y según el Dxcorrt en la de la derecha - Dosificación 2
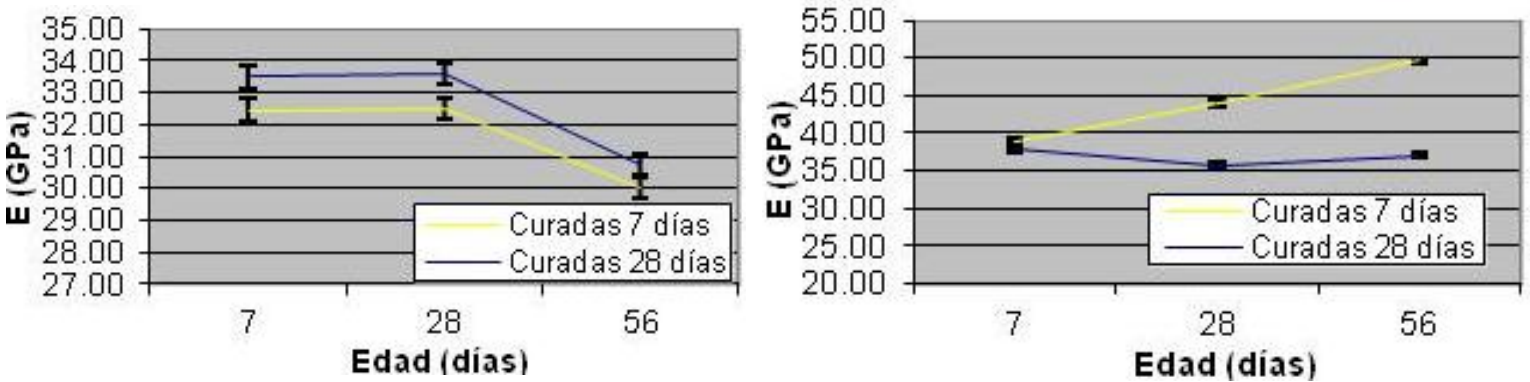

Figura 23. Influencia del tiempo de curado sobre la evolución del módulo elástico según el algoritmo Delay en la figura de la izquierda y según el Dxcorrt en la de la derecha - Dosificación 3 

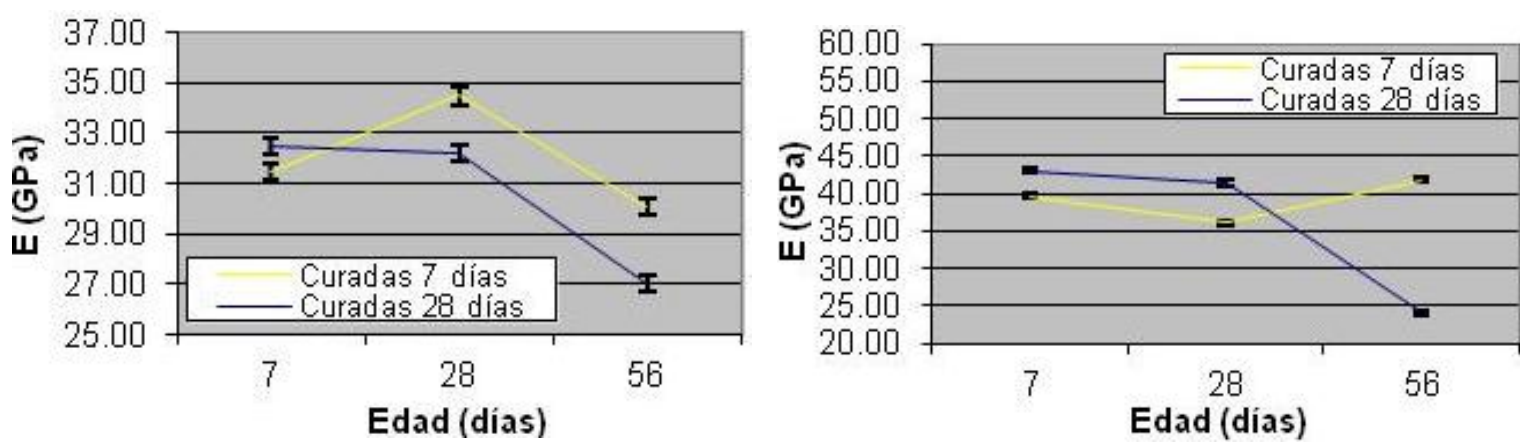

Figura 24. Influencia del tiempo de curado sobre la evolución del módulo elástico según el algoritmo Delay en la figura de la izquierda y según el Dxcorrt en la de la derecha - Dosificación 4
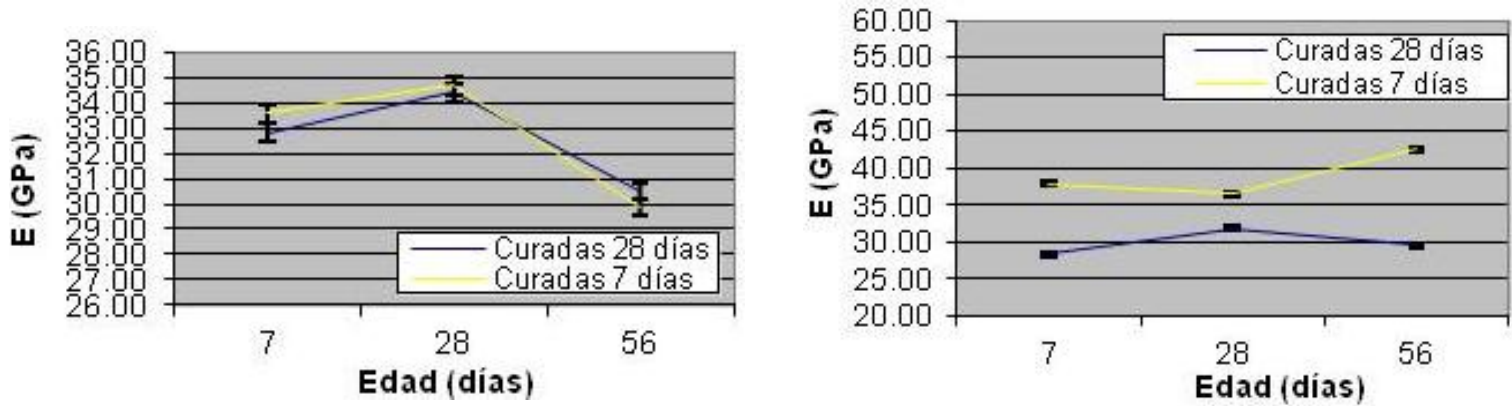

Figura 25. Influencia del tiempo de curado sobre la evolución del módulo elástico según el algoritmo Delay en la figura de la izquierda y según el Dxcorrt en la de la derecha - Dosificación 6
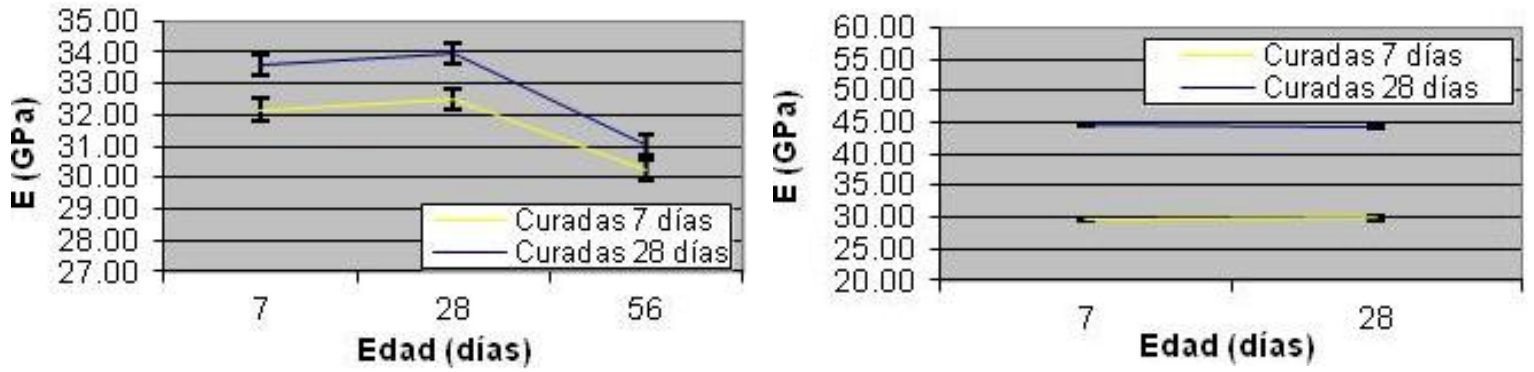

Figura 26. Influencia del tiempo de curado sobre la evolución del módulo elástico según el algoritmo Delay en la figura de la izquierda y según el Dxcorrt en la de la derecha - Dosificación 7
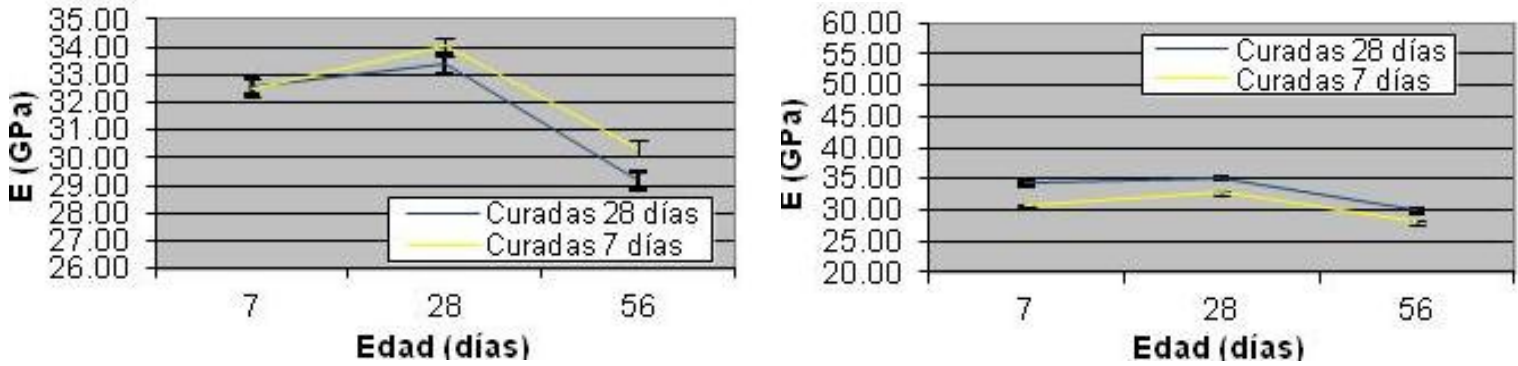

Figura 27. Influencia del tiempo de curado sobre la evolución del módulo elástico según el algoritmo Delay en la figura de la izquierda y según el Dxcorrt en la de la derecha - Dosificación 8
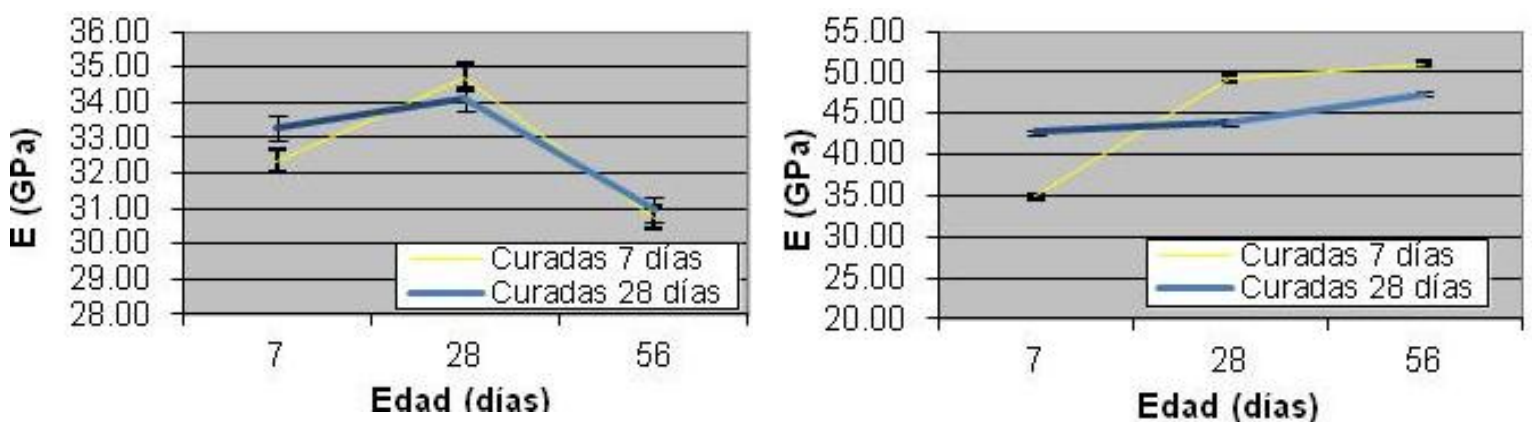

Figura 28. Influencia del tiempo de curado sobre la evolución del módulo elástico según el algoritmo Delay en la figura de la izquierda y según el Dxcorrt en la de la derecha - Dosificación 9 


\subsubsection{INFLUENCIA DE LA FRECUENCIA DE EXCITACIÓN EN EL RETARDO DE LAS ONDAS P Y EN EL MÓDULO ELÁSTICO}

\section{Retardo de ondas $\mathbf{P}$}

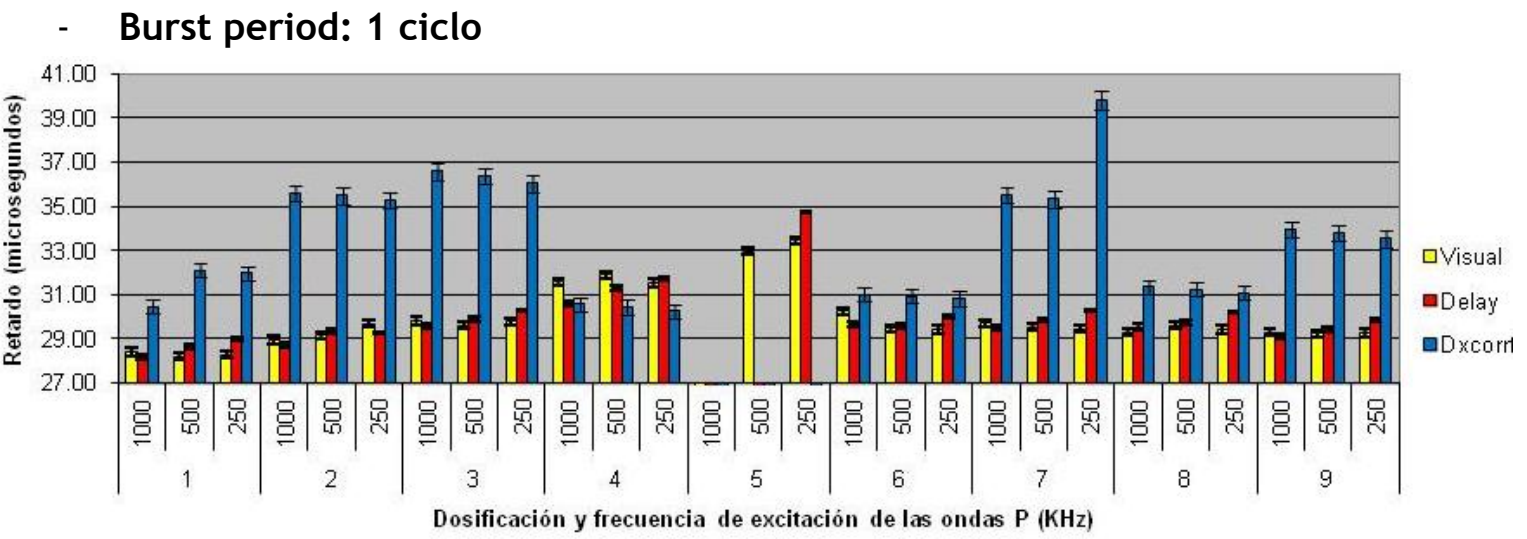

Figura 29. Influencia de la frecuencia de excitación sobre el retardo de ondas $\mathrm{P}$

\section{- Burst period: 5 ciclos}

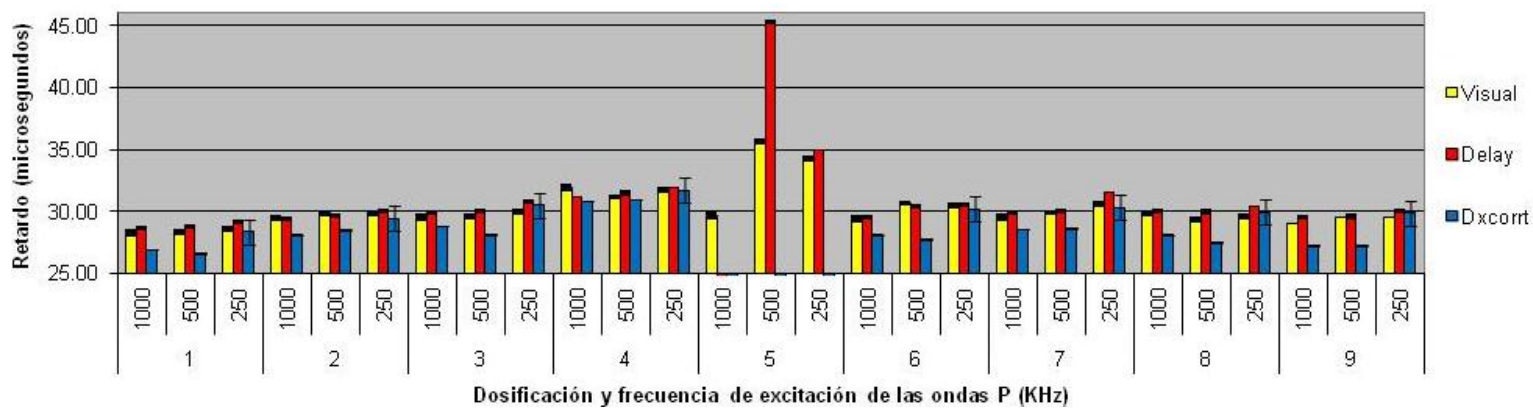

Figura 30. Influencia de la frecuencia de excitación sobre el retardo de ondas $P$

\section{Módulo elástico}

\section{A una determinada edad}

\section{- Burst period: 1 ciclo}

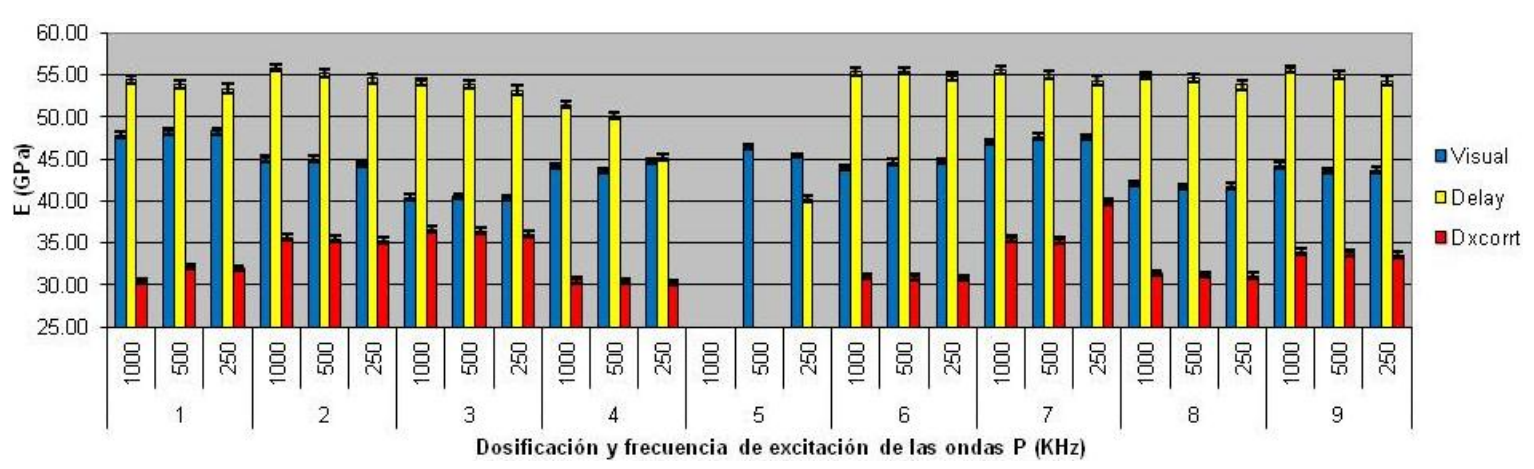

Figura 31. Influencia de la frecuencia de excitación sobre el módulo elástico 
- Burst period: 5 ciclos

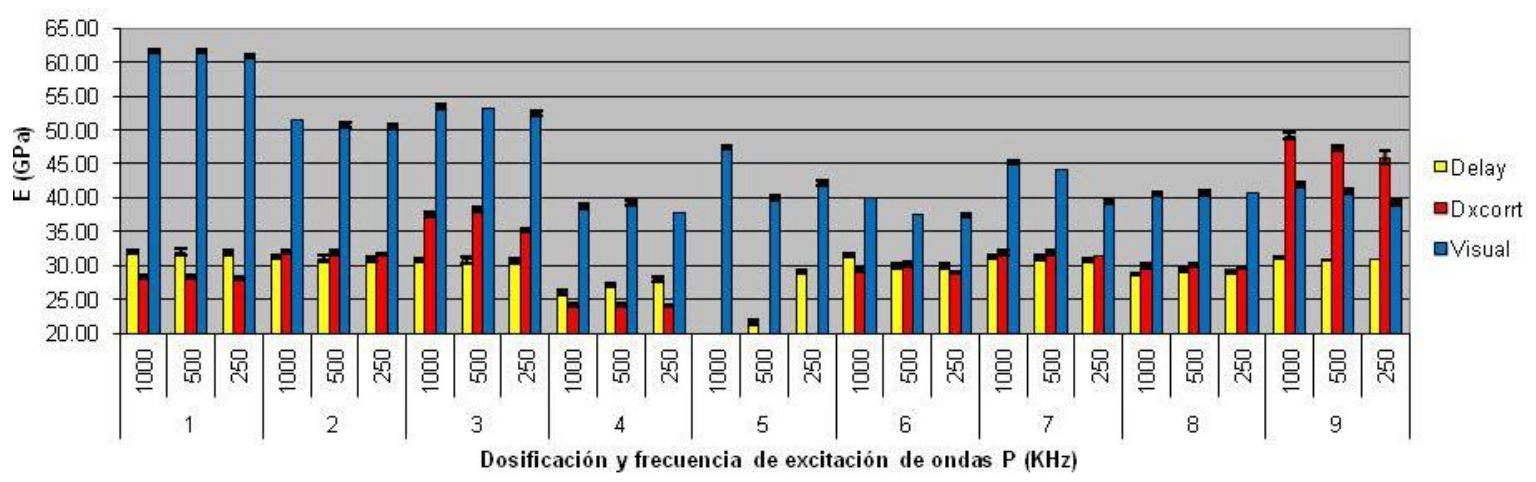

Figura 32. Influencia de la frecuencia de excitación sobre el módulo elástico

\section{Evolución en el tiempo}

- Burst period: 1 ciclo

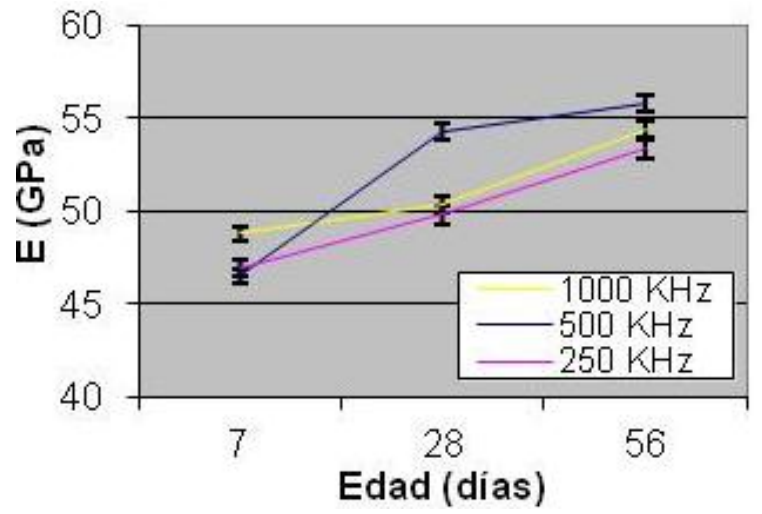

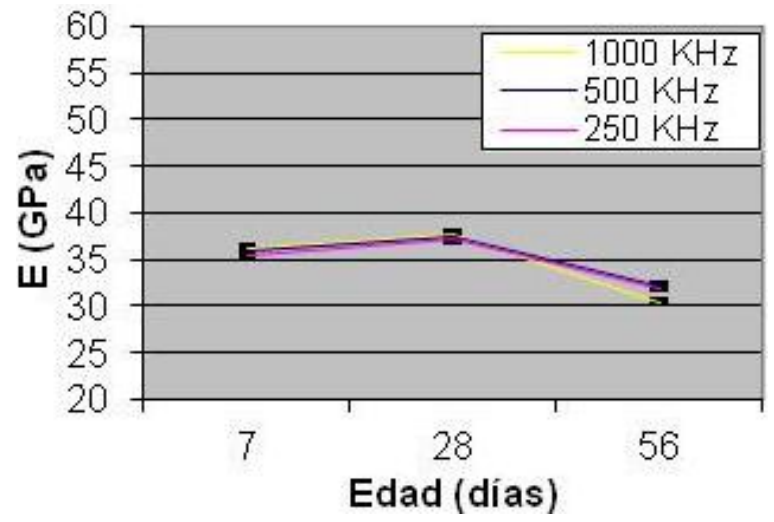

Figura 33. Influencia de la frecuencia de excitación sobre el módulo elástico y su evolución en la dosificación 1, estando representados a la izquierda los resultados obtenidos mediante el algoritmo Delay y a la derecha mediante Dxcorrt
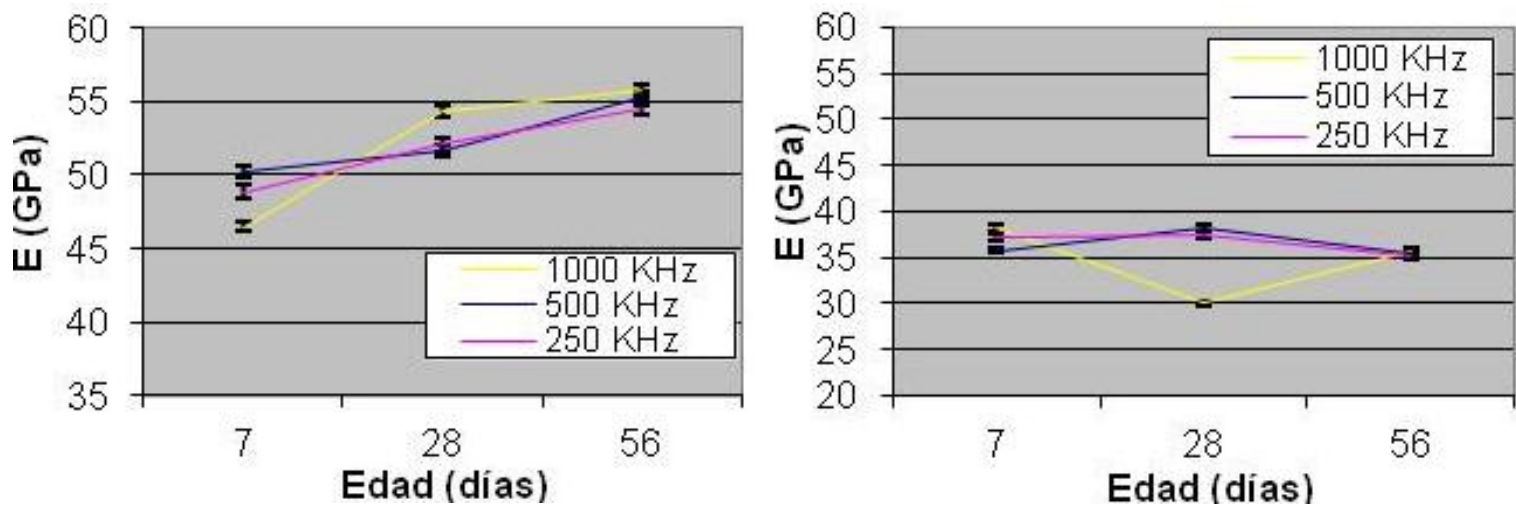

Figura 34. Influencia de la frecuencia de excitación sobre el módulo elástico y su evolución en la dosificación 2, estando representados a la izquierda los resultados obtenidos mediante el algoritmo Delay y a la derecha mediante Dxcorrt 

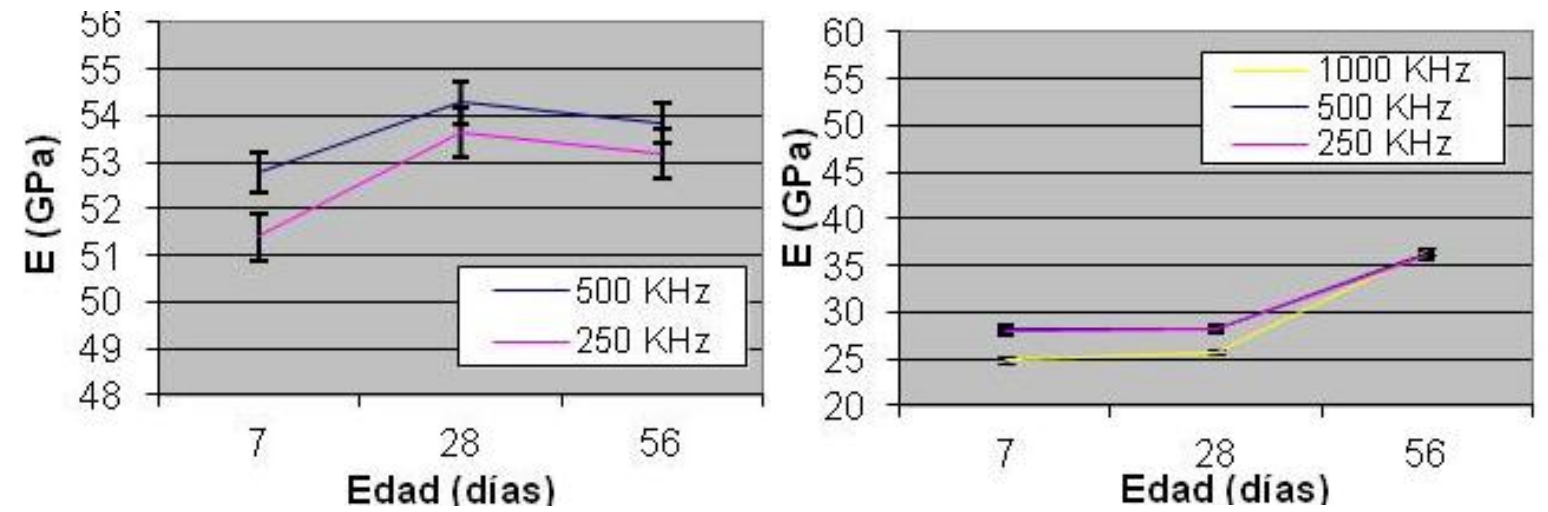

Figura 35. Influencia de la frecuencia de excitación sobre el módulo elástico y su evolución en la dosificación 3, estando representados a la izquierda los resultados obtenidos mediante el algoritmo Delay y a la derecha mediante Dxcorrt
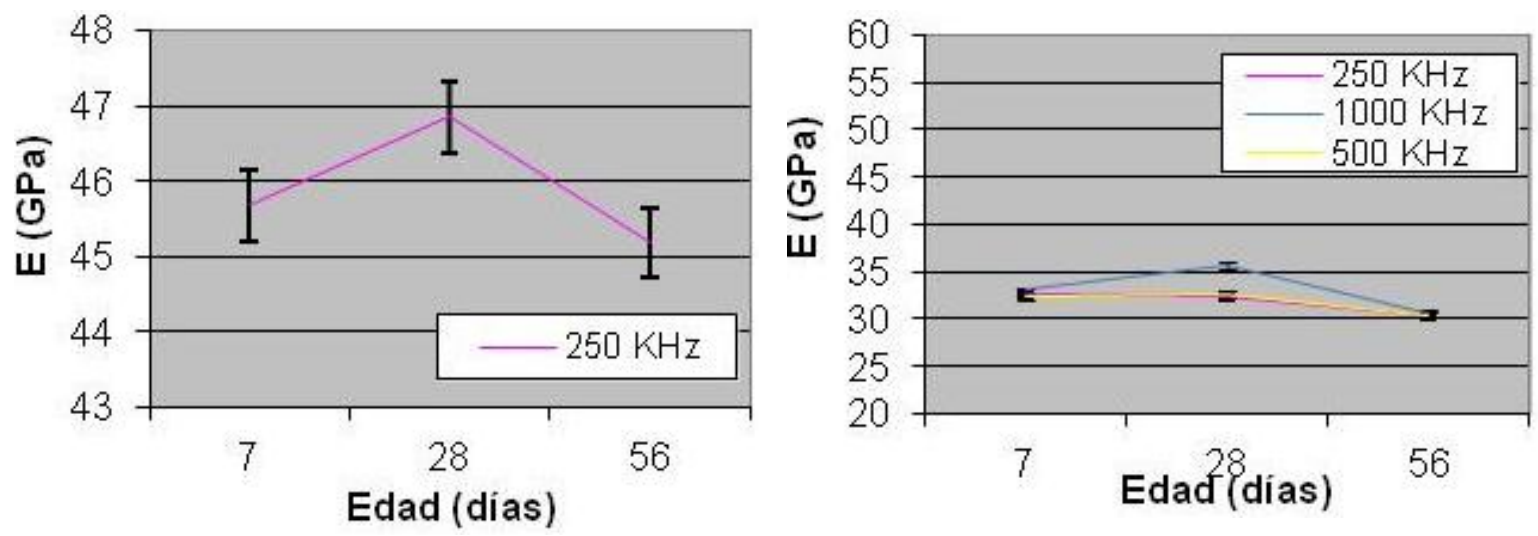

Figura 36. Influencia de la frecuencia de excitación sobre el módulo elástico y su evolución en la dosificación 4, estando representados a la izquierda los resultados obtenidos mediante el algoritmo Delay y a la derecha mediante Dxcorrt
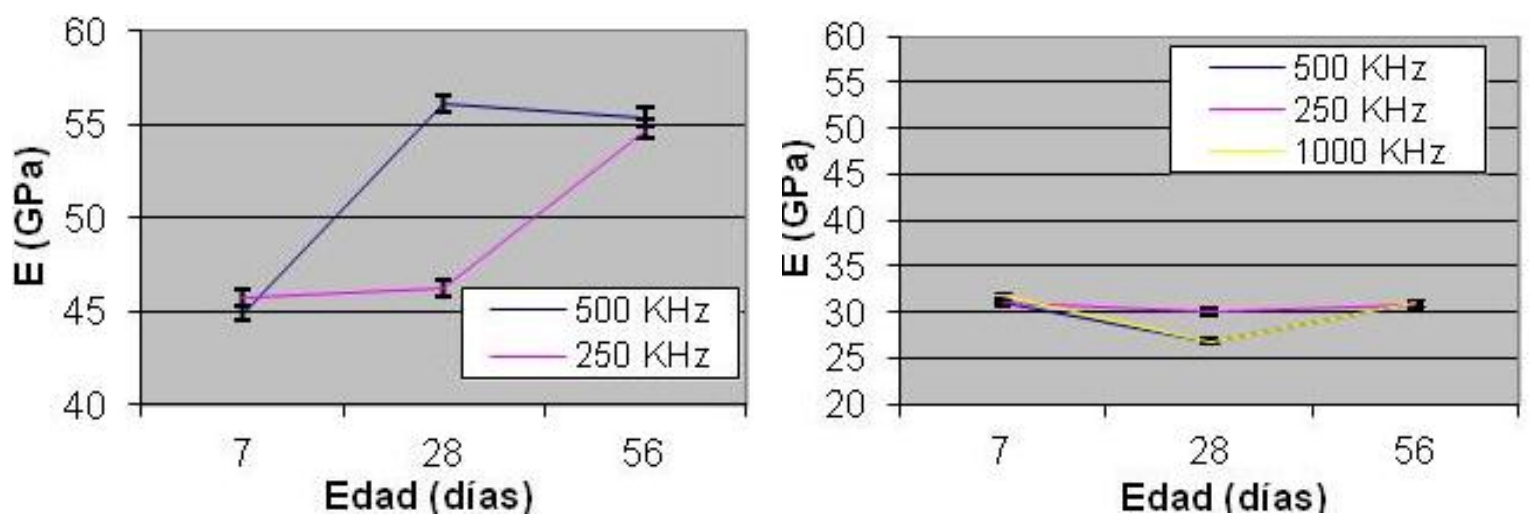

Figura 37. Influencia de la frecuencia de excitación sobre el módulo elástico y su evolución en la dosificación 6 , estando representados a la izquierda los resultados obtenidos mediante el algoritmo Delay y a la derecha mediante Dxcorrt 

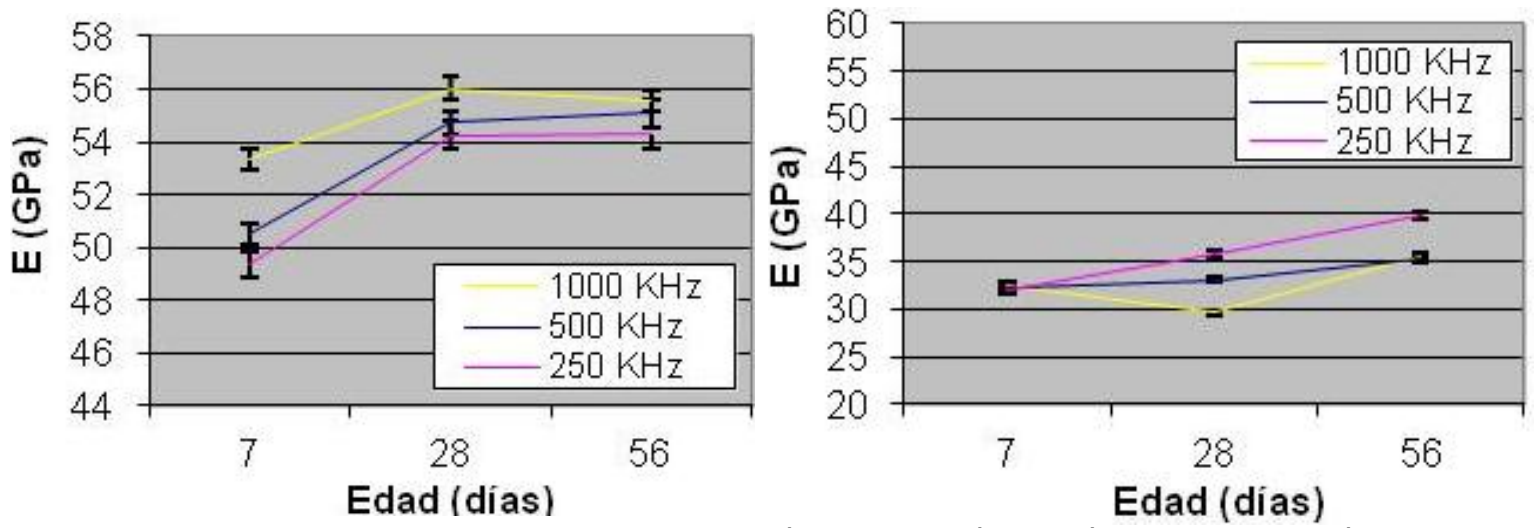

Figura 38. Influencia de la frecuencia de excitación sobre el módulo elástico y su evolución en la dosificación 7, estando representados a la izquierda los resultados obtenidos mediante el algoritmo Delay y a la derecha mediante Dxcorrt
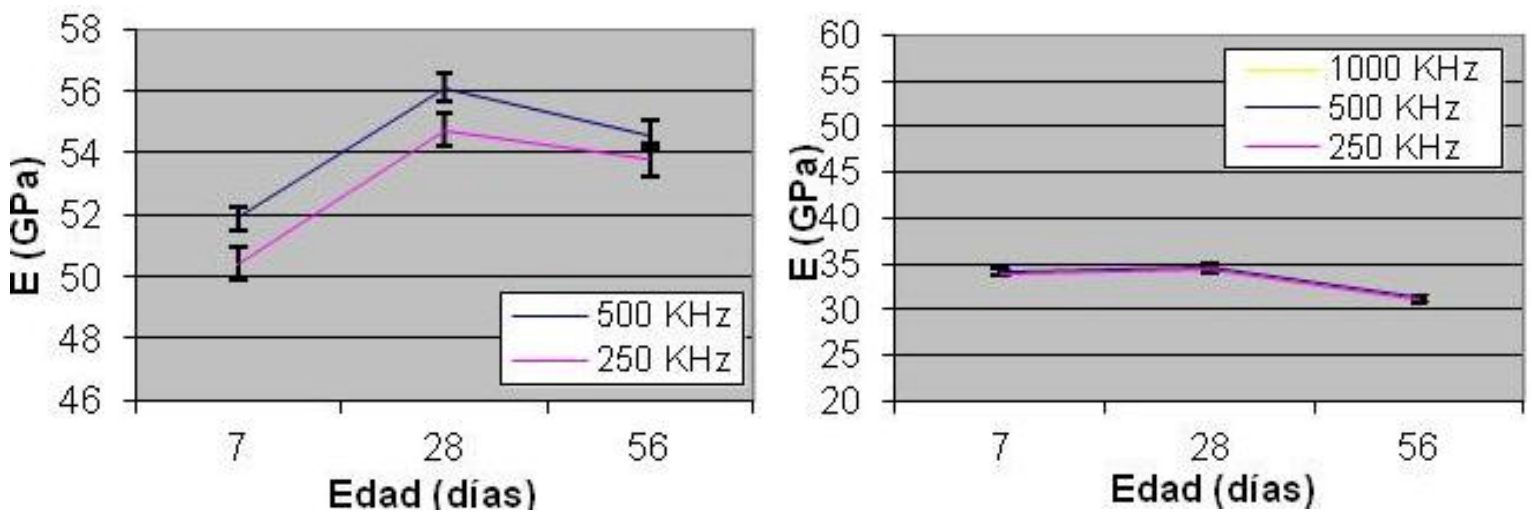

Figura 39. Influencia de la frecuencia de excitación sobre el módulo elástico y su evolución en la dosificación 8, estando representados a la izquierda los resultados obtenidos mediante el algoritmo Delay y a la derecha mediante Dxcorrt

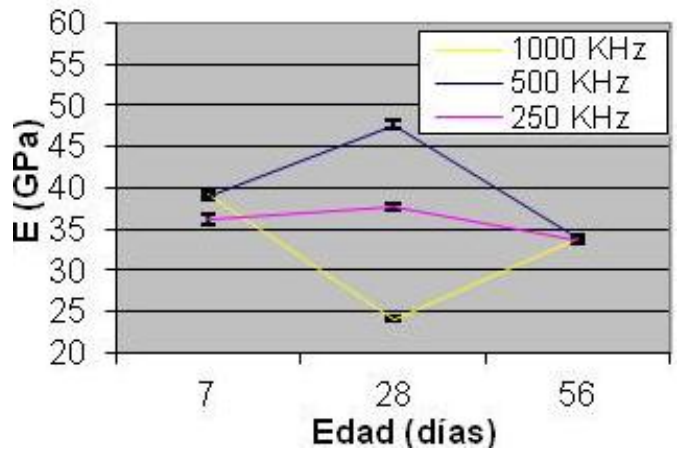

Figura 40. Influencia de la frecuencia de excitación sobre el módulo elástico y su evolución en la dosificación 9, obtenida mediante el algoritmo Dxcorrt
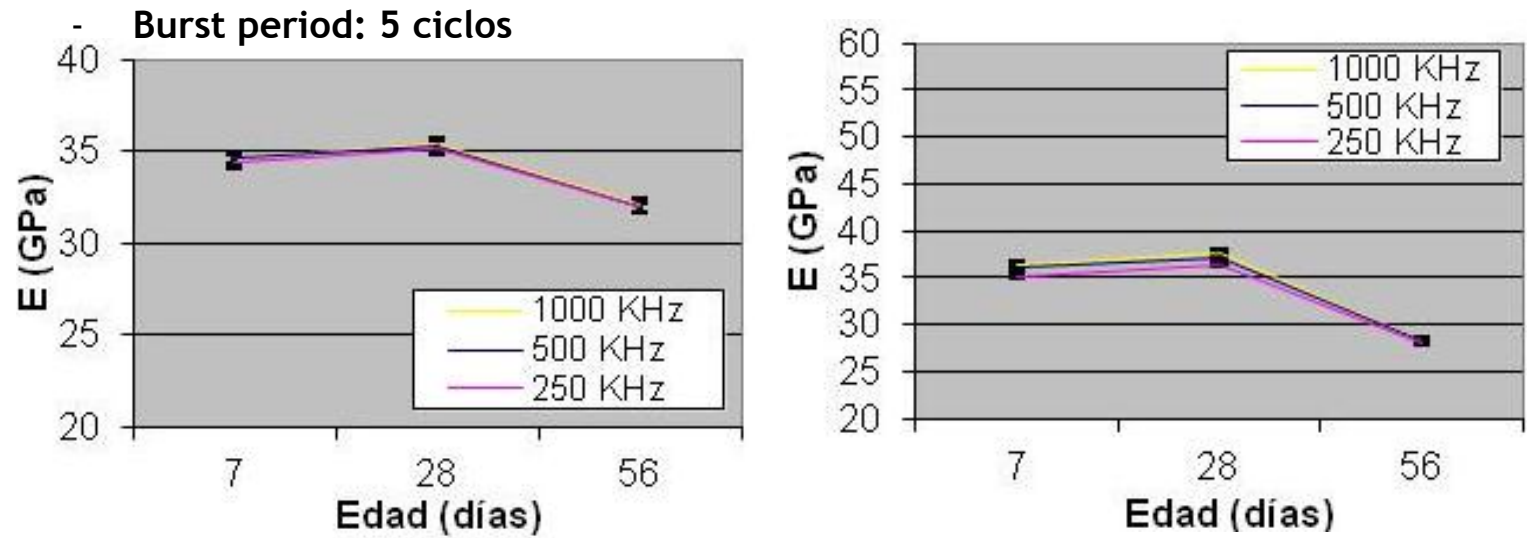

Figura 41. Influencia de la frecuencia de excitación sobre el módulo elástico y su evolución en la dosificación 1, estando representados a la izquierda los resultados obtenidos mediante el algoritmo Delay y a la derecha mediante Dxcorrt 

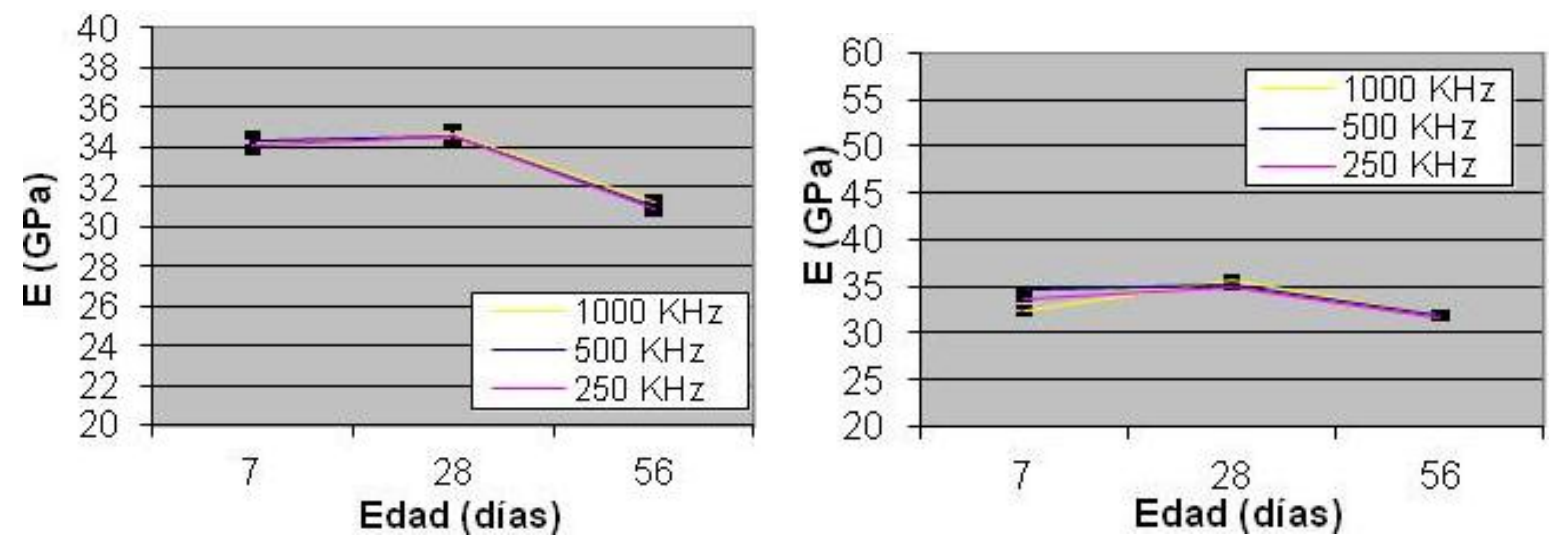

Figura 42. Influencia de la frecuencia de excitación sobre el módulo elástico y su evolución en la dosificación 2, estando representados a la izquierda los resultados obtenidos mediante el algoritmo Delay y a la derecha mediante Dxcorrt
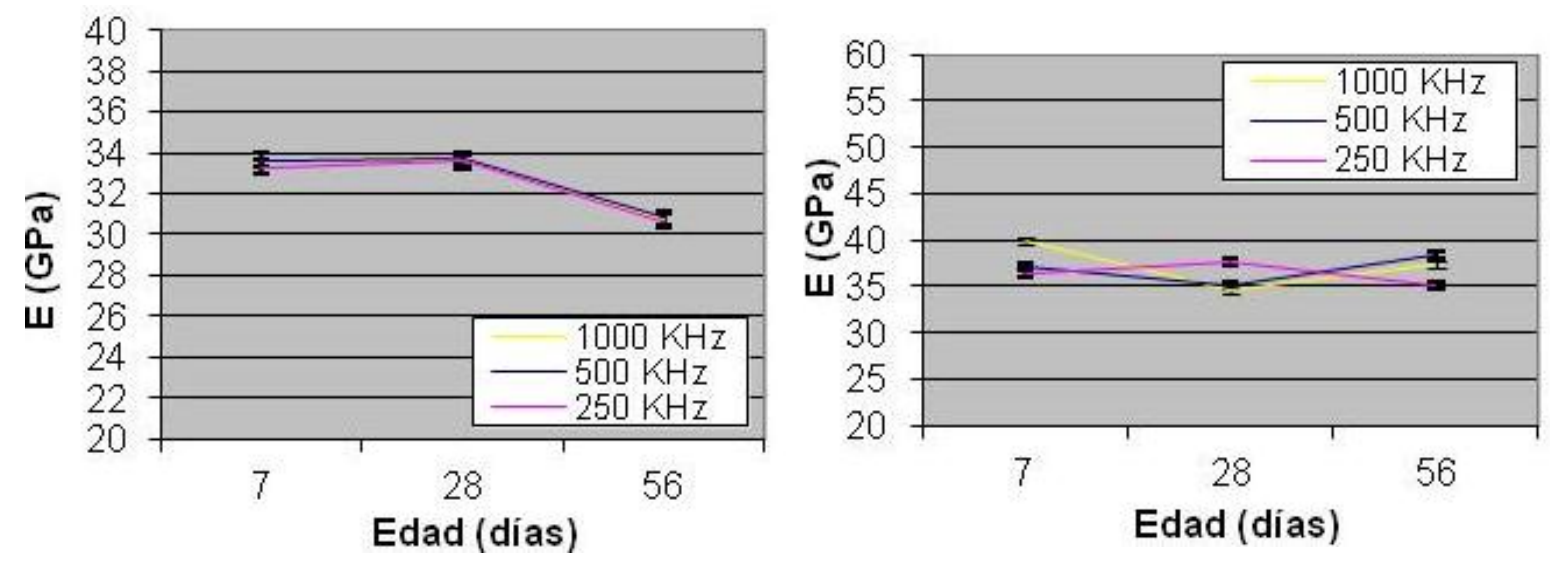

Figura 43. Influencia de la frecuencia de excitación sobre el módulo elástico y su evolución en la dosificación 3, estando representados a la izquierda los resultados obtenidos mediante el algoritmo Delay y a la derecha mediante Dxcorrt
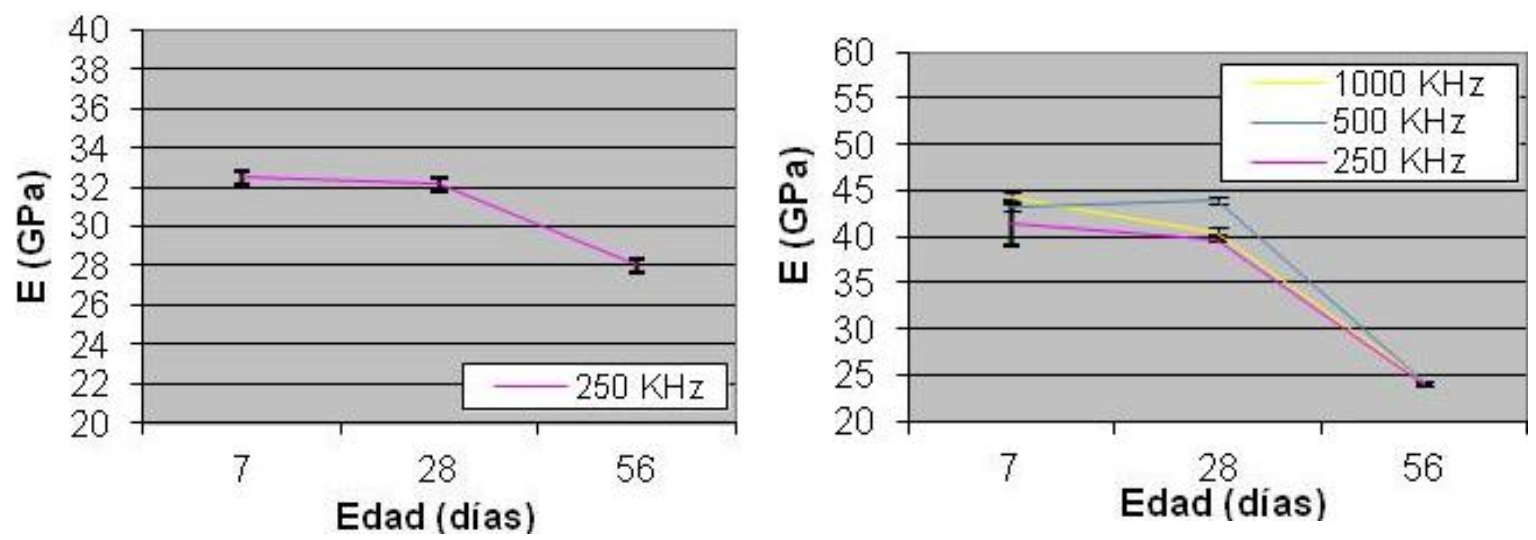

Figura 44. Influencia de la frecuencia de excitación sobre el módulo elástico y su evolución en la dosificación 4, estando representados a la izquierda los resultados obtenidos mediante el algoritmo Delay y a la derecha mediante Dxcorrt 

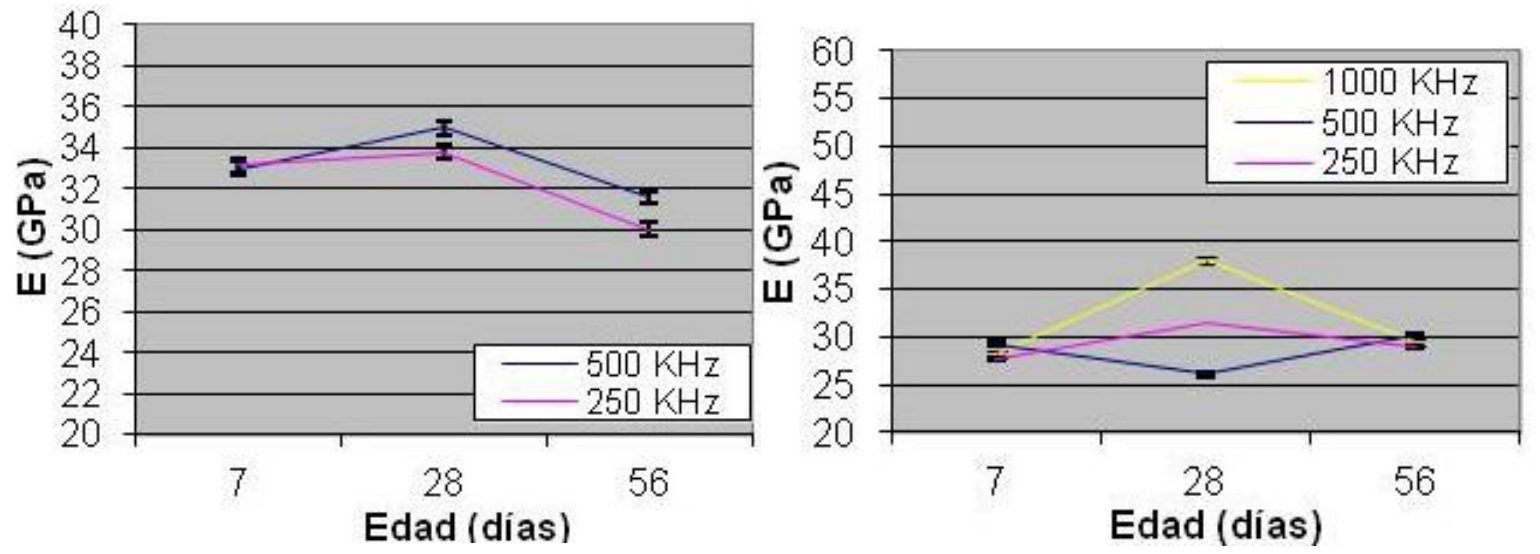

Figura 45. Influencia de la frecuencia de excitación sobre el módulo elástico y su evolución en la dosificación 6 , estando representados a la izquierda los resultados obtenidos mediante el algoritmo Delay y a la derecha mediante Dxcorrt
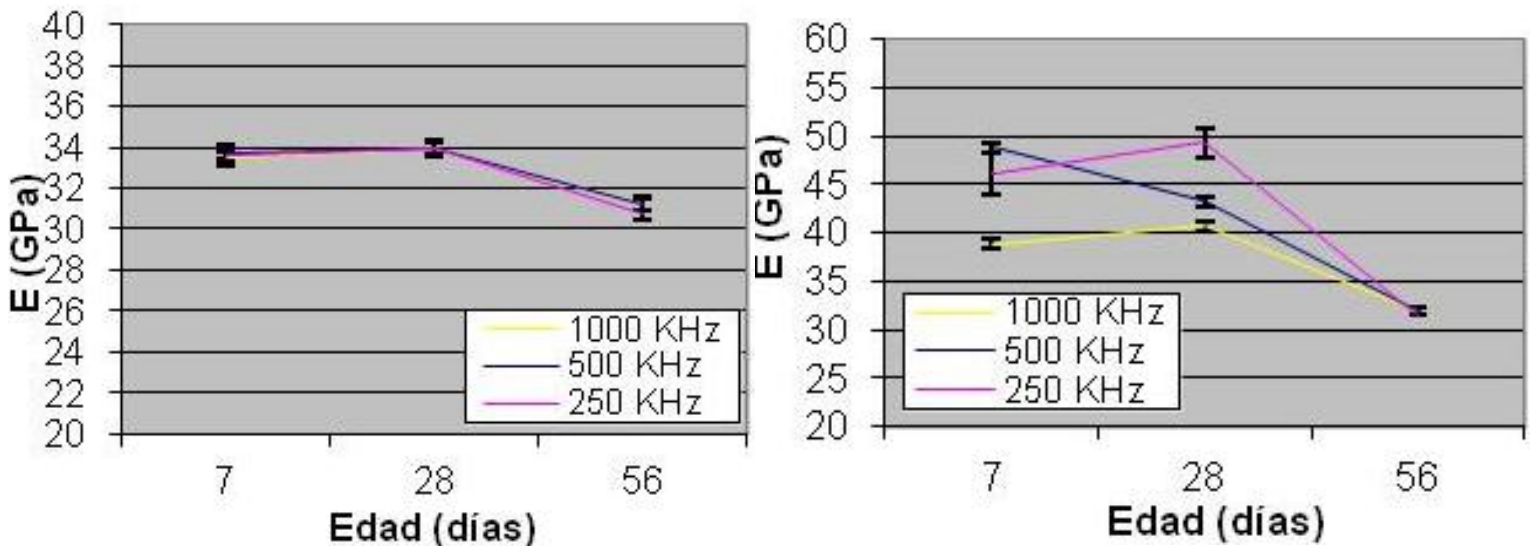

Figura 46. Influencia de la frecuencia de excitación sobre el módulo elástico y su evolución en la dosificación 7, estando representados a la izquierda los resultados obtenidos mediante el algoritmo Delay y a la derecha mediante Dxcorrt
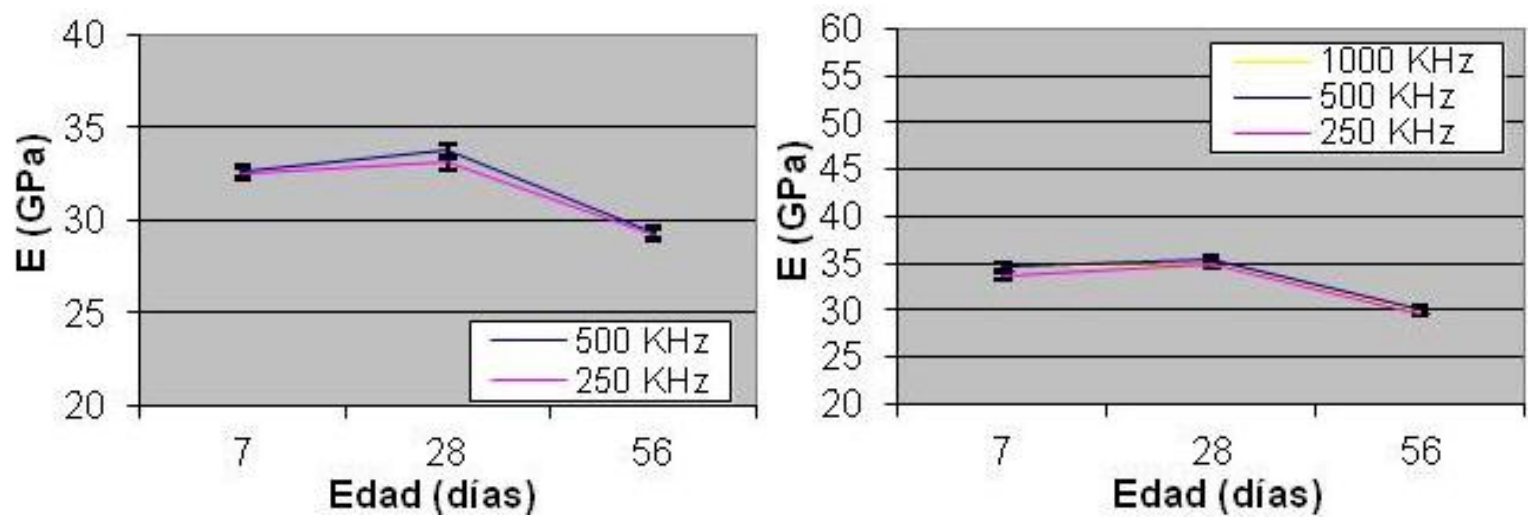

Figura 47. Influencia de la frecuencia de excitación sobre el módulo elástico y su evolución en la dosificación 8 , estando representados a la izquierda los resultados obtenidos mediante el algoritmo Delay y a la derecha mediante Dxcorrt 

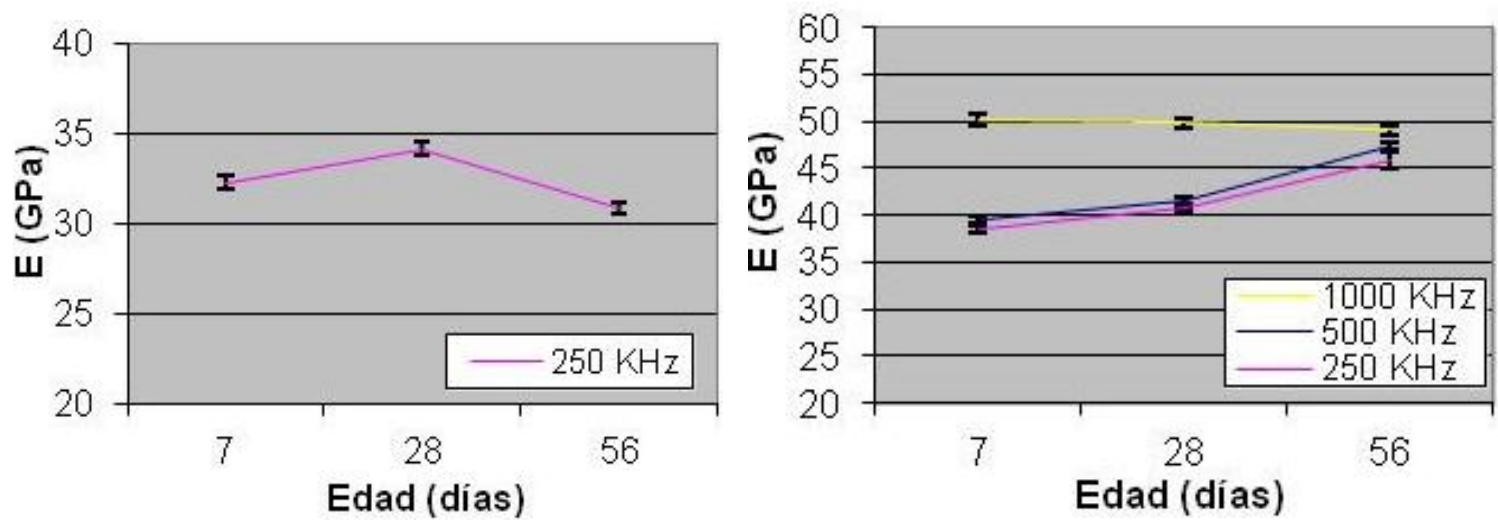

Figura 48. Influencia de la frecuencia de excitación sobre el módulo elástico y su evolución en la dosificación 9 , estando representados a la izquierda los resultados obtenidos mediante el algoritmo Delay y a la derecha mediante Dxcorrt

\section{CONCLUSIONES}

\subsection{MÉTODOS DE CÁLCULO DE RETARDO}

Como puede deducirse del estudio, y como ya se comentó anteriormente, se ha comprobado que el método visual es el peor de los propuestos, luego podría ser desestimable.

Por otro lado, sería necesario un fuerte estudio de comparación entre el resto de métodos para deducir cuál es el que mejor se aproxima a la realidad, y que en este estudio no se ha llevado a cabo de forma muy extensa, salvo mediante con la comparación de resistencias. Luego queda pendiente de evaluar definitivamente qué método es el idóneo.

\subsection{DOSIFICACIÓN ÓPTIMA}

Para la elección de la dosis óptima se ha puesto especial atención a los resultados del ensayo de flexotracción realizado según la normativa UNE.

Se ha observado que con 0,8 \% sph (sobre el peso del hormigón) de FV de $12 \mathrm{~mm}$ se consigue una resistencia a flexotracción alta; con dosis superiores $(1,1 \%)$, no aumenta apenas nada y elevarla, por tanto, por encima de ese porcentaje no compensaría por el consiguiente aumento de precio que se produciría. Cuando se trata de FV largas, el 0,8 $\%$ sph consigue igualmente una resistencia a flexotracción alta y, para elevarla más, es necesario subir la dosis a $1,5 \%$, lo que no se justifica por el considerable aumento de precio que conlleva en relación con la pequeña mejora estructural que produce en el hormigón.

El deterioro que sufre la resistencia a compresión del hormigón al introducir FV en su interior es despreciable para todas las dosis empleadas en este estudio. Por tanto, la resistencia a compresión no es un parámetro influyente para decidir la dosis.

Para que el HRFV sea rentable, la dosis debe ser menor de 1,5\%, de modo que esto también se ha tenido en cuenta a la hora de dosificar las FV. 
Existen otros parámetros que influyen en la dosis de FV, como es la energía de deformación. A falta de estudio detallado, se estima que una proporción del 1,6\% sph proporciona una energía de deformación más que suficiente.

Por tanto, la mejor dosificación podría ser una solución híbrida que combinase $0,8 \% \mathrm{sph}$ de FV cortas y el mismo porcentaje de FV largas.

No obstante, para optimizar aún más la dosis, se deberían evaluar no sólo las propiedades de resistencia a compresión y flexotracción, sino que se debería realizar un estudio más detallado de la capacidad de absorción de energía y del coste económico, entre otros. Queda pendiente pues la incorporación de estos parámetros a un siguiente estudio.

\subsection{PROPUESTAS DE MEJORA, LÍNEAS FUTURAS DE INVESTIGACIÓN Y APLICACIONES}

- Se está pensando, para el futuro inmediato, en la redacción de un artículo, conjuntamente con la AIE Estructuras y Pavimentos Discontinuos, que recoja, además de lo estudiado aquí, otros aspectos más relacionados con el Anejo 14 de la EHE en aplicación práctica de los ensayos elaborados y ,en especial, considerando los criterios elásticos o plásticos y los coeficientes en cada caso; en este sentido, ya se están incluso solicitando presupuestos a algunas empresas para la realización del ensayo EN 14651.

- Otro objetivo a muy corto plazo es redactar una guía de aplicación del HRFV, en la que se ofrezcan diferentes dosis de FV atendiendo a las características estructurales que el constructor requiera para su hormigón. En esta guía, cada variable estructural irá acompañada de su variabilidad asociada, lo que será un indicativo de calidad y fiabilidad para el constructor que desee apostar por el HRFV como producto constructivo.

- El diseño de la mezcla es un aspecto al que se le ha otorgado prioridad. Por un lado, la búsqueda afinada de la dosis óptima de FV es un aspecto que se va a estudiar con detalle. Se ha pensado en desarrollar un algoritmo que, en base a criterios económicos y estructurales, proporcione la dosificación óptima del HRFV que el constructor necesite. Por otro lado, se quiere confeccionar y evaluar un HRFV mixto, que incorpore fibras cortas y largas, ya que se prevé mejorarían consustancialmente las propiedades del hormigón. La fibra de menor longitud elevaría la resistencia a flexotracción y las fibras de longitud mayor permitirían más deformación para la carga pico de rotura, es decir, ayudarían a conseguir un comportamiento dúctil, que garantizaría cierta seguridad estructural tras la rotura, dejando las estructuras incluso unidas durante un tiempo después de producirse.

- Se pretenden inventar sendos modelos directo e inverso: un modelo que, dada una dosificación de un cierto HRFV, deduzca el módulo elástico del espécimen y otro que, dado el módulo elástico requerido, pueda diseñar la dosis óptima de fibras.

- Se pretende estudiar, sobre estas mismas probetas, otro aspecto muy interesante, y que no se ha podido estudiar, por necesitar que las probetas adquieran una edad determinada de vida, y que es la durabilidad del HRFV. Este aspecto es uno de los que más preocupa a los ingenieros que utilizan este material de construcción. En este sentido, se está pensando en estudiar varios factores que se sabe afectan a la 
durabilidad, y que podrían ser erradicados o, al menos, controlados, con tratamientos superficiales, por ejemplo.

- Pretende estudiarse también la microfisuración, existente incluso a niveles inferiores a las cargas de rotura de este material.

- Se prestará atención en investigaciones futuras también al proceso de desgarre de las FV sobre la propia matriz de cemento, y al proceso de arrancamiento de las mismas.

- Se seguirá investigando en los métodos propuestos e incluso se diseñarán nuevos mediante la combinación de éstos (como mezclar excitaciones de un ciclo para unas ondas y de cinco para otras) siempre buscando una mejora en los resultados a obtener.

- Pueden emplearse otros ensayos no destructivos como el método del martillo de impacto a través del análisis SASW o el método del elemento viga, propuesto en [6], y que relaciona el módulo de elasticidad dinámico con la frecuencia natural de vibración de una viga simplemente apoyada y sus características geométricas y físicas mediante la siguiente expresión

$$
E=\frac{4 m f^{2} l^{4}}{I \pi^{2} n^{4}}
$$

Donde

$\mathrm{m}$ masa de la viga por unidad de longitud

f frecuencia natural

n modo de vibración

I longitud de viga simplemente apoyada

I momento de inercia

Las mejoras en el HRFV son un constante desafío para todo ingeniero o científico, y en este sentido se seguirá intentando aportar el conocimiento que se siga adquiriendo sobre el tema.

\section{BIBLIOGRAFIA}

[1] R. Drai *, F. Sellidj, M. Khelil, A. Benchaala. Elaboration of some signal processing algorithms in ultrasonic techniques: application to materials NDT. Ultrasonics 38 (2000) 503-507.

[2] State-of-the-art report on fiber reinforced concrete. ACI 544.1R-96.

[3] Measurements of properties of fiber reinforced concrete. ACI 544.2R-89. 
[4] Non destructive methods for evaluation of concrete in structures. ACI 228.2R-98.

[5] Model code 2010. Part 5 Materials, 5.6 Fibers/fiber-reinforced concrete

[6] L. Zheng, X. Sharon Huo, Y. Yuan. Experimental investigation on dynamic properties of rubberized concrete. Construction and Building Materials 22 (2008) 939-947

[7] Abdessalem Benammar, Redouane Drai, Abderrezak Guessoum. Detection of delamination defects in CFRP materials using ultrasonics signal processing. Ultrasonics 48 (2008) 731-738

[8] Abbate A., Koay J., Schroeder SC., Das P. Signal detection and noise suppression using a wavelet transform signal processor: application to ultrasonic flaw detection. IEEE Trans Ultrason Ferroelect Freq Control (1997); 44(1): 14-26

[9] EHE 2008. Instrucción de hormigón structural, en especial el Anejo 14. Recomendaciones para la construcción de hormigones con fibras. 